\title{
Increased Ir-Ir Interaction in Iridium Oxide during the Oxygen Evolution Reaction at High Potentials Probed by Operando Spectroscopy
}

Steffen Czioska, Alexey Boubnov,* Daniel Escalera-López, Janis Geppert, Alexandra Zagalskaya, Philipp Röse, Erisa Saraçi, Vitaly Alexandrov, Ulrike Krewer, Serhiy Cherevko,* and Jan-Dierk Grunwaldt*

Cite This: ACS Catal. 2021, 11, 10043-10057

Read Online

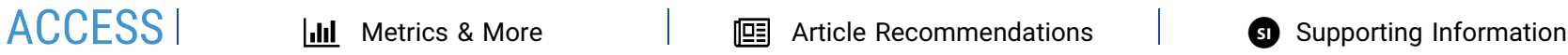

ABSTRACT: The structure of $\mathrm{IrO}_{2}$ during the oxygen evolution reaction (OER) was studied by operando X-ray absorption spectroscopy (XAS) at the Ir $\mathrm{L}_{3}$-edge to gain insight into the processes that occur during the electrocatalytic reaction at the anode during water electrolysis. For this purpose, calcined and uncalcined $\mathrm{IrO}_{2}$ nanoparticles were tested in an operando spectroelectrochemical cell. In situ XAS under different applied potentials uncovered strong structural changes when changing the potential. Modulation excitation spectroscopy combined with XAS enhanced the information on the dynamic changes significantly. Principal component analysis (PCA) of the resulting spectra as well as FEFF9 calculations uncovered that both the $\mathrm{Ir}_{3}$-edge energy and the white line intensity changed due to the formation of

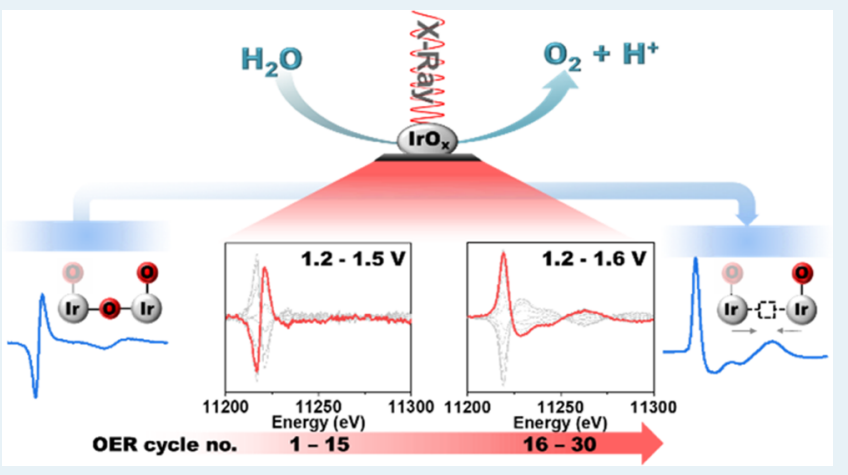
oxygen vacancies and lower oxidation state of iridium at higher potentials, respectively. The deconvoluted spectra and their components lead to two different OER modes. It was observed that at higher OER potentials, the well-known OER mechanisms need to be modified, which is also associated with the stabilization of the catalyst, as confirmed by in situ inductively coupled plasma mass spectrometry (ICP-MS). At these elevated OER potentials above $1.5 \mathrm{~V}$, stronger Ir-Ir interactions were observed. They were more dominant in the calcined $\mathrm{IrO}_{2}$ samples than in the uncalcined ones. The stronger $\mathrm{Ir}-\mathrm{Ir}$ interaction upon vacancy formation is also supported by theoretical studies. We propose that this may be a crucial factor in the increased dissolution stability of the $\mathrm{IrO}_{2}$ catalyst after calcination. The results presented here provide additional insights into the OER in acid media and demonstrate a powerful technique for quantifying the differences in mechanisms on different OER electrocatalysts. Furthermore, insights into the OER at a fundamental level are provided, which will contribute to further understanding of the reaction mechanisms in water electrolysis.

KEYWORDS: oxygen evolution reaction, in situ XAS, water splitting, iridium oxide, dissolution stability, modulation excitation spectroscopy, flame spray pyrolysis

\section{INTRODUCTION}

Green hydrogen from electrocatalytic water splitting is regarded as one of the most promising energy carriers to balance the intermittent nature of renewable energies. Although considerable research activities have already been undertaken in the development and optimization of electrocatalysts, their catalytic processes and surface properties during hydrogen production are still not fully understood. ${ }^{1}$ This is especially true under the dynamic conditions inherent to renewable electricity, which poses a challenge when competing with conventional power sources. ${ }^{2}$ Electrochemical water electrolysis consists of the hydrogen evolution reaction (HER) at the cathode and the oxygen evolution reaction (OER) at the anode. Compared to the readily occurring HER, sluggish kinetics and high overpotentials hamper the OER. Due to its high-current density and relatively low-temperature requirements, proton exchange membrane (PEM) water electrolysis is one of the preferred electrolysis technologies. ${ }^{3}$ However, in the acidic environment prevalent in such setups, very few materials are stable and exhibit reasonable electrocatalytic efficiency. ${ }^{4}$ Materials commonly used to catalyze the

Received: May 7, 2021

Revised: June 18, 2021

Published: July 29, 2021 
OER in PEM water electrolyzers (PEMWEs) are Ir- and Ruoxides, ${ }^{5}$ which are increasingly scarce and expensive. Ir-based materials have higher electrochemical stability, but they are less active, whereas Ru-based catalysts present higher performances but also lower stability and thus higher dissolution rates. ${ }^{5}$ One factor that strongly influences the dissolution stability and performance of Ir- and Ru-based OER catalysts is the calcination process. After calcination, the dissolution stability of the catalyst increases at the expense of the OER performances. $^{6-8}$ The increased stability and lower OER performance were initially attributed to a higher crystalline structure but are not yet fully understood. ${ }^{9}$

The OER in the acidic electrolyte is suggested to proceed according to the two different reaction mechanisms regarding the origin of oxygen, the adsorbate evolution mechanism (AEM) and the lattice oxygen mechanism (LOM). In the AEM, water molecules are absorbed at the surface and lose protons to form hydroxides, oxyhydroxides, and hydroperoxides until molecular oxygen is released. ${ }^{10,11}$ While the AEM is well understood, the LOM is more complex. ${ }^{12}$ There are several hypotheses, but they all have in common the participation of lattice oxygen, in which the evolved oxygen is formed partly from the electrolyte and partly from the oxide structure. ${ }^{9,12-14}$ On the one hand, this leads to a faster OER, but, on the other hand, it reduces the catalyst stability, as formed oxygen vacancies destabilize the electrocatalyst structure. $^{15}$

X-ray absorption spectroscopy (XAS) is a suitable technique to investigate catalytic reactions due to its ability to resolve structural changes and oxidation states. However, the sensitivity of XAS with respect to minority species is usually comparatively weak, as it is a bulk-sensitive method. Higher sensitivity has been achieved using a high dispersion ${ }^{16,17}$ of the element of interest or by selectively placing atoms on the surface. ${ }^{18,19}$ In addition, the application of transient experiments that increase the response of some spectroscopic signals has proven to be a suitable method to detect the structure of the catalytically active species. For instance, modulation excitation spectroscopy (MES) ${ }^{20}$ is one such method, where the system under investigation is excited by periodically changing the selected conditions (e.g., potential, $\mathrm{pH}$, concentration, temperature, type of reactants), while the measurements proceed continuously. Due to the increased information gain, MES is used in a variety of time-resolved spectroscopic techniques such as XAS, X-ray diffraction (XRD), IR, and Raman spectroscopy. ${ }^{21-28}$ One way to analyze the spectroscopic data from a modulation excitation experiment is to use phase-sensitive detection (PSD). The resulting phase-resolved spectra obtained from PSD analysis provide signals from those species that respond with the same frequency as that at which the externally applied stimulus is varied. This makes it possible to extract signals from highly dynamic short-lived or low abundant species that are otherwise difficult to observe. In this respect, quick-XAS (also called QEXAFS) is an advanced X-ray absorption spectroscopy method that makes it possible to acquire XAS spectra at a high rate $\left(1 \mathrm{~s} /\right.$ spectrum or faster) for data acquisition. ${ }^{29}$ With this technique, one can either observe phenomena that occur on a very fast scale or eliminate noise in the measurements by averaging over a large number of spectra. The high-quality quick-XAS spectra are key to the further analysis of the XAS data, as shown in the present work.
Prior XAS investigations on $\mathrm{IrO}_{2}$ OER catalysts have been performed at lower OER potentials, below $1.5 \mathrm{~V}$ vs reversible hydrogen electrode (RHE), given the strong bubble evolution occurring at higher OER potentials, which complicates in situ XAS investigations above this potential. ${ }^{30-33}$ All of these studies show a change of the $\mathrm{IrO}_{2}$ electrocatalyst to higher oxidation states with increasing potential. Ex situ measurements by Abbott et al. ${ }^{32}$ show reduction of the electrocatalyst after electrochemical cycling up to a higher potential of $1.6 \mathrm{~V}$. This was hypothesized to be related to an increased number of $\mathrm{Ir}^{3+}$. Recently, by investigating the Tafel slopes on various $\mathrm{IrO}_{x}$-based OER catalysts, it was found that above $1.5 \mathrm{~V}$, a change in kinetic behavior is observed, ${ }^{34}$ which is not fully understood.

Despite intensive research to further understand the OER mechanism, many processes occurring on the catalyst surface during reaction conditions remain unclear. In addition, the role of calcination in determining which mechanism is taking place, which ultimately affects both dissolution stability and OER activity, is still not fully understood and poses an important scientific question to the electrocatalyst synthesis community.

In this study, we aimed to gain a better understanding of the electrocatalytic OER mechanism of the Ir-based catalysts at both low as well as high OER potentials. For this purpose, we used nanocrystalline Ir-based catalysts prepared by flame spray pyrolysis (FSP) in an as-prepared and calcined state. Operando XAS was used to investigate the $\mathrm{IrO}_{2}$ electrocatalysts during the OER under steady-state conditions with varying potentials and then under a modulating potential. The latter resulted in modulation excitation XAS, which is more sensitive to the dynamic species in the catalyst. ${ }^{35}$ Principal component analysis (PCA) was performed to deconvolute the spectra into different sets of components for monitoring the changes that occurred. The analysis and assignment of the principal components were conducted by calculating model spectra using the FEFF9 $\operatorname{code}^{36}$ and supported by density functional theory (DFT) calculations. Complementary to PCA, these results were deepened by difference spectra and multivariate curve resolution-alternating least square (MCR-ALS) analysis. Additionally, the behavior at alternating potentials between preOER and OER conditions was elucidated by MES. In situ measurements with inductively coupled plasma mass spectrometry (ICP-MS) coupled to an electrochemical scanning flow cell (SFC) setup were performed to gain insight into the stabilization of the catalyst when switching between the alternating pre-OER and OER potential conditions, analogous to the MES protocol. The goal was to gain a more comprehensive insight into the OER mechanisms in an acidic medium as a function of different reaction conditions and catalyst structures and in this way to contribute to the understanding and optimization of the OER process both in steady as well as dynamic operating conditions.

\section{EXPERIMENTAL SECTION}

Materials and Ex Situ OER Performance. The $\mathrm{IrO}_{2}$ nanoparticle electrocatalysts were synthesized by flame spray pyrolysis (FSP). ${ }^{37,38}$ In brief, flame spray pyrolysis (FSP) is a synthesis method in which a metal salt precursor dissolved in an organic liquid is sprayed into a flame, combusted, and collected on filter paper using back pressure created by a vacuum system. ${ }^{39}$ In this study, $1 \mathrm{~g}$ of metal salt precursor, namely, iridium acetylacetonate, was dissolved in a mixture of $50 \mathrm{~mL}$ of equal parts of acetic acid and methanol. 
Subsequently, the solution was ultrasonicated for $1 \mathrm{~h}$ to ensure complete dissolution of the metal salt. The solutions were filled in $50 \mathrm{~mL}$ syringes and placed in a syringe pump (Legato 210, $\mathrm{KD}$ Scientific Inc.). At a flow of $5 \mathrm{~mL} \mathrm{~min}^{-1}$, the solutions were fed to the FSP nozzle and released through a $0.413 \mathrm{~mm}$ diameter steel capillary (Hamilton syringes, KF6, gauge 22)

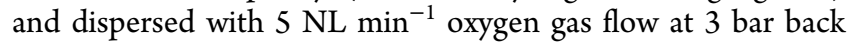
pressure. The dispersed solution was ignited by a supporting flame of $0.75 \mathrm{NL} \mathrm{min}^{-1}$ methane and $1.6 \mathrm{NL} \mathrm{m^{-1 }}$ oxygen flow. The product particles were collected on a glass fiber filter (Whatman GF6, GE) in a cylindrical filter holder $80 \mathrm{~cm}$ over the flame, which was connected to a vacuum pump (R5, Busch). The nozzle and the glass fiber filter were water-cooled. Finally, the solid powder was collected by scraping it off the filters. The as-prepared catalyst will be denoted " $\mathrm{IrO}_{2}$ uncalcined" hereafter. In addition, the freshly FSP-prepared $\mathrm{IrO}_{2}$ catalyst was placed in a calcination furnace and heated to $600{ }^{\circ} \mathrm{C}$ for $2 \mathrm{~h}$ in air (heating ramp of $2{ }^{\circ} \mathrm{C} \mathrm{min}{ }^{-1}$ ), referred to in this study as " $\mathrm{IrO}_{2}$ calcined".

Cyclic voltammetry measurements were carried out on a Gamry 600+ and a Gamry 3000 potentiostat (Gamry Instruments) using a Teflon cell and an MSR electrode rotator (Pine Research) equipped with a glassy carbon working electrode $(\varnothing 5.0 \mathrm{~mm})$ coated with an $\mathrm{IrO}_{2}$ catalyst and a platinum wire counter electrode. The potentials were normalized to a RHE reference electrode (Hydroflex, Gaskatel $\mathrm{GmbH}$ ). A $0.1 \mathrm{M}$ aqueous acidic $\mathrm{H}_{2} \mathrm{SO}_{4}$ electrolyte was used for all electrochemical experiments. Before each measurement, the solution was purged with argon (99.999\%, Air Liquide).

Freshly polished glassy carbon working electrodes were used for drop-casting the $\mathrm{IrO}_{2}$ ink. The $\mathrm{IrO}_{2}$-containing ink was prepared as follows: $2.5 \mathrm{mg}$ of $\mathrm{IrO}_{2}$ nanoparticles, $8.58 \mu \mathrm{L}$ of Nafion 5\% in $\mathrm{H}_{2} \mathrm{O}$ /isopropanol (w/w) (D520, VWR), and 1.2 $\mu \mathrm{L}$ of $1 \mathrm{M} \mathrm{KOH}$ ( $\mathrm{pH}$ adjustment to ca. 11) were dispersed in $250 \mu \mathrm{L}$ of isopropanol and $750 \mu \mathrm{L}$ of deionized $\mathrm{H}_{2} \mathrm{O}(>16.2$ $\mathrm{M} \Omega$ ). The mixture was sonicated for $10 \mathrm{~min}$ and another 5 min before each drop-casting. Subsequently, $5 \mu \mathrm{L}$ of ink were drop-casted onto the electrode and dried at $60{ }^{\circ} \mathrm{C}$ for at least $30 \mathrm{~min}$. This procedure was repeated to achieve a final dropcasted ink volume of $10 \mu \mathrm{L}$ per tested electrode, yielding a catalyst loading of $127 \mu \mathrm{g}_{\text {catalyst }} \mathrm{cm}_{\text {geom }}{ }^{-2}$.

Cyclic voltammetry experiments were carried out at ambient temperature. The potential window ranged from 0.05 to $1.6 \mathrm{~V}$ vs RHE. Measurements were performed sequentially at scan rates of $200,100,50,25$, and $200 \mathrm{mV} \mathrm{s}^{-1}$, with three cyclic voltammograms per scan rate.

Characterization of Materials. Catalyst particle size and morphology were studied using an FEI Titan 80-300 transmission electron microscope (TEM) operated at a 300 $\mathrm{kV}$ acceleration voltage in a high-angle annular dark-field scanning mode. X-ray diffraction (XRD) patterns were acquired using a Bruker D8 Advance diffractometer using $\mathrm{Cu}$ $\mathrm{K} \alpha$ radiation $(\lambda=1.54 \AA$, an accelerating electron voltage of 40 $\mathrm{kV}$, an anode current of $35 \mathrm{~mA}$ ). The intensity of scattered Xrays was measured in a $2 \theta$-range of $20-90^{\circ}$, a step width of $0.0164^{\circ}, 1$ step s$^{-1}$.

Electrochemical Dissolution Testing. For investigations of the dissolution stability, the electrochemical tests with the scanning flow cell (SFC) were performed with a LabVIEWcontrolled Gamry Reference 600+ potentiostat (Gamry), consisting of a graphite rod counter electrode compartment (6 mm diameter, 99.995\%, Sigma-Aldrich) and a doublejunction $\mathrm{Ag} / \mathrm{AgCl}$ reference electrode compartment (Met- rohm, Switzerland; an outer compartment filled with $0.1 \mathrm{M}$ $\mathrm{HClO}_{4}$, an inner compartment with the standard $3 \mathrm{M} \mathrm{KCl}$ electrolyte). Both compartments were connected to the main cell body with Tygon tubing (internal diameter: $1.02 \mathrm{~mm}$ ). The V-shaped polycarbonate SFC was CNC machined inhouse (CAM 4-02 Impression Gold, vhf camfacture AG, Germany), presenting an elliptical-shaped opening at the flow channels intersect, providing a working electrode area of 0.033 $\mathrm{cm}^{2}$. Catalyst testing with the SFC system was carried out by drop-casting $\mathrm{IrO}_{2}$ nanoparticle inks onto a mirror-polished glassy carbon plate $\left(50 \times 50 \times 3 \mathrm{~mm}^{2}\right.$, HTW, Sigradur $)$. $\mathrm{IrO}_{2}$ inks were prepared by dispersing $1.775 \mathrm{mg}$ of $\mathrm{IrO}_{2} \mathrm{FSP}$ nanopowdered catalysts in a mixed aqueous solution containing an 87.5/12.5 volume-to-volume ratio of ultrapure DI water (Merck, Milli-Q IQ 7000, 18.2 M $\Omega \mathrm{cm}$ ) and isopropanol (Merck, Emsure). Then, $10.15 \mu \mathrm{L}$ of a Nafion solution ( 5 wt \%, Sigma-Aldrich) was added to obtain a catalyst-to-ionomer ratio of 4:1, yielding an $\mathrm{IrO}_{2}$ ink concentration of $0.663 \mathrm{mg}_{\mathrm{Ir}} \mathrm{mL}^{-1}$. All inks were sonicated for $10 \mathrm{~min}(4 / 2 \mathrm{~s}$ on/off pulse intervals) with an ultrasonication horn (Branson, SFX 150) in an ice bath and further drop-casted using $0.2 \mu \mathrm{L}$ per catalyst spot $(\varnothing \mathrm{ca} .1 .3 \mathrm{~mm}$ ) to yield Ir catalyst loadings of ca. $10 \mu \mathrm{g}_{\mathrm{Ir}} \mathrm{cm}^{-2}$. For electrochemical testing, the SFC opening was vertically aligned to the catalyst spots by means of a top-view camera.

Real-time Ir dissolution data from the FSP-synthesized electrocatalysts were obtained by pumping a freshly prepared $0.1 \mathrm{M} \mathrm{H}_{2} \mathrm{SO}_{4}$ electrolyte (96\%, Suprapur, Merck) from an Arsaturated reservoir, downstream via the $\mathrm{V}$-shaped SFC channels, toward a PerkinElmer NexION 350× inductively coupled plasma mass spectrometer (ICP-MS) connected with poly(tetrafluoroethylene) (PTFE) tubing (internal diameter: $300 \mu \mathrm{m}$ ) at a constant flow rate of ca. $202 \mu \mathrm{L} \mathrm{min}{ }^{-1}$. The ICPMS instrument was calibrated against a four-point calibration curve obtained from standard solutions $(0,0.5,1$, and $5 \mu \mathrm{g}$ $\mathrm{L}^{-1}$ ) containing intentional amounts of Ir (Merck Certipur), using $10 \mu \mathrm{g} \mathrm{L}^{-1}{ }^{187} \mathrm{Re}$ as an internal standard. For additional information regarding the custom setup employed, we refer to previous publications ${ }^{7,40}$

X-ray Absorption Spectroscopy (XAS). X-ray absorption near-edge structure (XANES) and extended X-ray absorption fine structure (EXAFS) spectra were collected at the SuperXAS beamline $^{29}$ of the Swiss Light Source (SLS) (PSI, Villigen, Switzerland). The SLS operates under a top-up mode at 2.4 $\mathrm{GeV}$ electron energy and a current of $400 \mathrm{~mA}$. The incident beam was collimated by an Rh-coated mirror at $2.5 \mathrm{mrad}$ and monochromatized using a channel-cut $\mathrm{Si}(111)$ monochromator. The beam was focused with an Rh-coated toroidal mirror down to $100 \times 100 \mu \mathrm{m}^{2}$ at the sample position. The beamline energy was calibrated with $\mathrm{Pt}$ reference foil to the $\mathrm{Pt}_{3}$-edge position at $11564 \mathrm{eV}$. Ionization chambers filled with 2 bar of $\mathrm{N}_{2}$ were used for XAS detection in a transmission mode with an Ir reference foil measured simultaneously between the second and third ionization chambers.

Cell Preparation and Operando XAS Measurements. For the in situ XAS cell, catalyst ink suspensions for the working electrodes were prepared by dispersing the respective $\mathrm{IrO}_{2}$ powders in a mixture of ultrapure water $(18.2 \mathrm{M} \Omega \mathrm{cm}$, ELGA Purelabs Ultra), isopropanol (99.9\% Chromasolv Plus for high-performance liquid chromatography (HPLC), SigmaAldrich), and polymer binder (E5\% Nafion 117 solution, Sigma-Aldrich or 5\% Nafion D520 solution, Alfa Aesar). The resulting mixtures were placed in an ultrasonication bath for 15 
min to fully disperse the catalyst and Nafion ionomer. The ink composition employed for flow cell measurements consisted of $80 \mathrm{mg}$ of catalyst, $0.64 \mathrm{~mL}$ of water, $0.48 \mathrm{~mL}$ of isopropanol, and $0.32 \mathrm{~mL}$ of Nafion 117 solution (for an ionomer-tocatalyst mass ratio of $\approx 0.2$ ). The catalyst layers for these flow cell measurements were subsequently deposited by spray coating onto a gold-sputtered, pre-cut piece of conductive Kapton foil (DuPont Kapton 200RS100) with a circular, goldfree area of $4 \mathrm{~mm}$ in diameter. The final electrodes featured catalyst loadings of $\approx 3000$ to $\approx 5000 \mu \mathrm{g}_{\mathrm{IrO}_{x}} \mathrm{~cm}_{\text {geom }}{ }^{-2}$ (i.e., $\approx 30$ to $\approx 50$-fold larger than those used in the ring-disk electrode (RDE)-tests, vide supra), which were considered necessary to record high-quality XAS spectra in the transmission acquisition mode concomitant to these measurements (see ref 42 and the Experimental Section details below). The weighing and determination of the catalyst loading were performed according to a previous study using the same setup. ${ }^{41}$ Moreover, the flow cell is equipped with carbon-based counter electrodes made with equivalent procedures based on the ink of Nafion and Black Pearls 2000 carbon. An ink consisting of $100 \mathrm{mg}$ of Black Pearls 2000 carbon (Cabot Corp.), $1 \mathrm{~mL}$ of ionomer solution $(\approx 5 \%$ Nafion 117 solution, Sigma-Aldrichresulting in an ionomer-to-carbon mass ratio of $\approx 0.4), 6 \mathrm{~mL}$ of ultrapure water $(18.2 \mathrm{M} \Omega \mathrm{cm}$, ELGA Purelab Ultra), and $2 \mathrm{~mL}$ of isopropanol (99.9\% Chromasolv Plus for HPLC, SigmaAldrich) was prepared by ultrasonication. Using a mask placed on a hot plate at $100{ }^{\circ} \mathrm{C}$, this carbon-based ink was spraycoated on two $4 \mathrm{~mm}$ diameter areas of a gold-sputtered, precut piece of conductive Kapton foil (DuPont Kapton 200RS100), to yield a loading of $1.6 \mathrm{mg}_{\mathrm{C}} \mathrm{cm}^{-2}$. These two coated spots are located at the sides of a nonsputtered area of the same diameter that is upon electrochemical cell assembly aligned to the working electrode area to minimize any undesired beam absorption. As with the $\mathrm{IrO}_{x}$-based working electrodes, these counter electrodes were weighed using a microbalance (Mettler Toledo XPE206DR).

For the operando XAS measurements, we employed the electrochemical flow cell setup of Binninger et al. ${ }^{42}$ (see Figure S1). The cell consisted of polyetheretherketone (PEEK) and was equipped with the working electrode drop-cast coated with the catalyst under study, a counter electrode coated with carbon, and a reference $\mathrm{Ag} / \mathrm{AgCl}$ electrode upstream of the electrolyte flow. The electrolyte consisted of aqueous $0.1 \mathrm{M}$ $\mathrm{H}_{2} \mathrm{SO}_{4}$ saturated with $\mathrm{O}_{2}$ and drawn through the cell by a syringe pump at $50 \mu \mathrm{L} / \mathrm{min}$. With no membrane to separate the working and the counter electrodes, both the evolved oxygen and hydrogen were mixed downstream of the cell. The potentials were applied to the electrodes via a Biologic SP-300 potentiostat. The electrochemical potentials for the experiments were chosen to drive the OER at the measurable reaction threshold (low OER potential) and $0.1 \mathrm{~V}$ higher (high OER potential) but low enough to avoid vigorous gas evolution, which could compromise the XAS measurements.

Three experimental modes were used: (i) sequential $10 \mathrm{~min}$ potentiostatic holds at open-circuit potential (OCP), $1.2 \mathrm{~V}$, low OER potential, high OER potential, low OER potential, $1.2 \mathrm{~V}$ and OCP (designated as stable potential measurements); (ii) symmetrical potentiostatic staircase between $1.2 \mathrm{~V}$ (lower potential limit) and the high OER potential (higher potential limit) with $0.04 \mathrm{~V}$ increments, dwelling for 2 min per each potential step; and (iii) periodical potentiostatic steps between 1.2 $\mathrm{V}$-low OER and 1.2 $\mathrm{V}$-high OER for 15 periods, dwelling 2 min per step. The last electrochemical protocol was at the same time as modulation excitation XAS (MES) experiment, which was analyzed by demodulation to detect spectral features that changed in response to the periodic modulation. The experimental scheme with these three experimental modes is further illustrated in Scheme S1 in the Supporting Information (SI).

\section{RESULTS}

Uncalcined and Calcined $\mathrm{IrO}_{2}$ Nanoparticle Catalysts. The freshly synthesized $\mathrm{IrO}_{2}$ nanoparticles prepared by flame spray pyrolysis (FSP), referred to here as " $\mathrm{IrO}_{2}$ uncalcined", were received as a dark gray powder. To increase dissolution stability toward the OER, these particles were further calcined $\left(T=600{ }^{\circ} \mathrm{C}\right)$ to yield the dark black $\mathrm{IrO}_{2}$ sample designated as "IrO $\mathrm{I}_{2}$ calcined". For surface-driven processes such as electrochemical water splitting, catalyst particle size is a crucial factor since smaller sizes give larger surface areas and can ultimately reduce the amount of the precious catalyst loadings. Moreover, synthesizing particles with a high surface area benefits XAS measurements, as XAS is not a surface-sensitive method. In fact, the uncalcined $\mathrm{IrO}_{2}$ presented a highly porous structure consisting of small particle crystallites with an average size of about $2 \mathrm{~nm}$ (for more details, see Figure S2, SI). After calcination, highly crystalline nanoparticles with particle dimensions between 20 and $30 \mathrm{~nm}$ were obtained. XRD (Figure S2C) confirmed the structure of rutile $\mathrm{IrO}_{2}$ for the calcined sample. For the uncalcined sample, the rutile $\mathrm{IrO}_{2}$ reflections are strongly broadened beyond resolution due to the small particle sizes, which explain the absence of wellresolved diffraction patterns. Hence, the strong modification in the XRD patterns corroborates the crystallization of the $\mathrm{IrO}_{2}$ nanoparticles after calcination. The small reflections observable in the uncalcined sample relate to metallic Ir. This metallic Ir occurs commonly during the synthesis of rutile $\mathrm{IrO}_{2} \cdot{ }^{31,43-45}$ After calcination, these reflections are still observable, but comparison with the rutile $\mathrm{IrO}_{2}$ diffraction peaks shows that metallic Ir is only present in traces. Also, the Fourier-transform EXAFS spectra of $\mathrm{IrO}_{2}$ calcined and uncalcined at OCP (see later) show backscattering due to a metallic as well as an oxidic Ir-Ir shell, which further supports that both phases are present at the beginning of the measurement. This is also in agreement with previous studies ${ }^{32}$ (in which measured $\mathrm{IrO}_{2}$ showed a similar pattern in $k$-space as our samples, see Figure S3). The particles were characterized by cyclic voltammetry at different scan rates (Figures $\mathrm{S} 4$ and $\mathrm{S} 5$ ). $\mathrm{IrO}_{2}$ uncalcined shows a strong current in the pre-OER region, most likely due to different oxidation reactions (also see ref 57). These currents are much smaller in the calcined sample, which can be attributed to the increased particle size and the resulting reduced active surface area. Both samples show no OER performance until about 1.4 $\mathrm{V}$ vs RHE. For $\mathrm{IrO}_{2}$ uncalcined, $\mathrm{O}_{2}$ evolution starts at about $1.45 \mathrm{~V}$, and strong $\mathrm{O}_{2}$ evolution can be observed at $1.55 \mathrm{~V}$ vs RHE. For $\mathrm{IrO}_{2}$ calcined, oxygen evolution begins at higher potential values. Low oxygen evolution can be observed at about $1.5 \mathrm{~V}$, while strong oxygen evolution appears at $1.6 \mathrm{~V}$. Consequently, the two samples are an ideal selection for operando spectroscopic studies and these values (the marked lines in Figures S4 and S5 in the SI) indicate the potentials for the two samples, where the low and high OER are measured by operando XAS, highlighted in Table 1, and used throughout this study. 
Table 1. Two OER Catalysts and Their Characteristics Used in This Study (More Information in the ESI) as Well as OER Potentials vs RHE Employed in Operando XAS Electrochemical Experiments ${ }^{a}$

\begin{tabular}{ccccccc}
$\begin{array}{c}\text { OER } \\
\text { catalyst }\end{array}$ & synthesis & $\begin{array}{c}\text { particle } \\
\text { size } \\
(\mathrm{nm})\end{array}$ & $\begin{array}{c}\text { OCP } \\
(\mathbf{V})^{b}\end{array}$ & $\begin{array}{c}\text { sub- } \\
\text { OER } \\
(\mathrm{V})\end{array}$ & $\begin{array}{c}\text { low } \\
\text { OER } \\
(\mathbf{V})\end{array}$ & $\begin{array}{c}\text { high } \\
\text { OER } \\
(\mathbf{V})\end{array}$ \\
$\begin{array}{c}\mathrm{IrO}_{2} \\
\text { calcined }\end{array}$ & $\begin{array}{c}\text { FSP and } \\
\text { calcined at }\end{array}$ & $20-30$ & $\sim 1.2$ & 1.2 & 1.50 & 1.60 \\
$\quad 600{ }^{\circ} \mathrm{C}$ & & & & & \\
$\mathrm{IrO}_{2}$ & $\begin{array}{c}\mathrm{FSP} \text { and as- } \\
\text { prepared }\end{array}$ & $\sim 2$ & $\sim 1.2$ & 1.2 & 1.45 & 1.55 \\
\hline
\end{tabular}

${ }^{a}$ Open-circuit potential was determined experimentally for each sample. ${ }^{b}$ Open-circuit potential.

Operando XAS on $\mathrm{IrO}_{2}$ during the OER. Operando XAS electrochemical experiments were performed using an electrochemical flow cell setup by Binninger et al. ${ }^{42}$ (schematic view in Figure S1). Figure 1A,D presents the recorded electrochemical currents during the operando experiments for each catalyst after sequential 10 min potentiostatic hold phases in a symmetric pyramid shape. The duration of the holding allows the system to equilibrate in between the steps and consequently reach steady-state conditions at pre-OER and OER potentials. For $\mathrm{IrO}_{2}$ calcined, applied potentials were changed from OCP $\sim 0.7$ to $1.2,1.5$, and $1.6 \mathrm{~V}$ and were subsequently symmetrically decreased back to OCP. In the case of uncalcined $\mathrm{IrO}_{2}$, potentials were applied from OCP to $1.2,1.45$, and $1.55 \mathrm{~V}$ and were symmetrically reduced, similar to the calcined sample. The catalyst loadings and applied OER potentials were optimized according to the activity differences between the calcined and uncalcined $\mathrm{IrO}_{2}$, listed in Table 1 . High OER bubble formation would otherwise create disturbances during XAS spectra acquisition, compromising data quality.

As expected, higher applied potentials result in higher OER currents, with the highest performance obtained at 1.6 and $1.55 \mathrm{~V}$ for the calcined and uncalcined samples, respectively. For full E/I graphs, see Figures S6 and S7. For the calcined sample, an increase in the OER current is seen during the initial and final potentiostatic holds at $1.5 \mathrm{~V}$, which would tentatively indicate an activation of the catalyst. For the uncalcined sample, a small drop in current is already observed at $1.45 \mathrm{~V}$, which can be attributed to the dissolution of the catalyst. This agrees with previous investigations, ${ }^{9,46-48}$ which showed much higher dissolution stability for the calcined sample. For both samples, a decrease in current is observed during the applied highest OER potentials (1.6 and $1.55 \mathrm{~V}$, respectively), which is attributed to bubble accumulation on the electrode.

Figure 1B,E shows the XANES spectra of $\mathrm{IrO}_{2}$ calcined and $\mathrm{IrO}_{2}$ uncalcined (additional data of these measurements are shown in Figures S8 and S9). Despite the careful choice of electrochemical potentials, the higher OER potential holding steps caused strong bubble formation, which temporarily distorted the XAS signal. Nevertheless, due to the high number of spectra taken (averaged over 600 spectra for each graph in Figure 1A,D), it was possible to gain a clear signal that averaged out all disturbances arising from bubble evolution. In
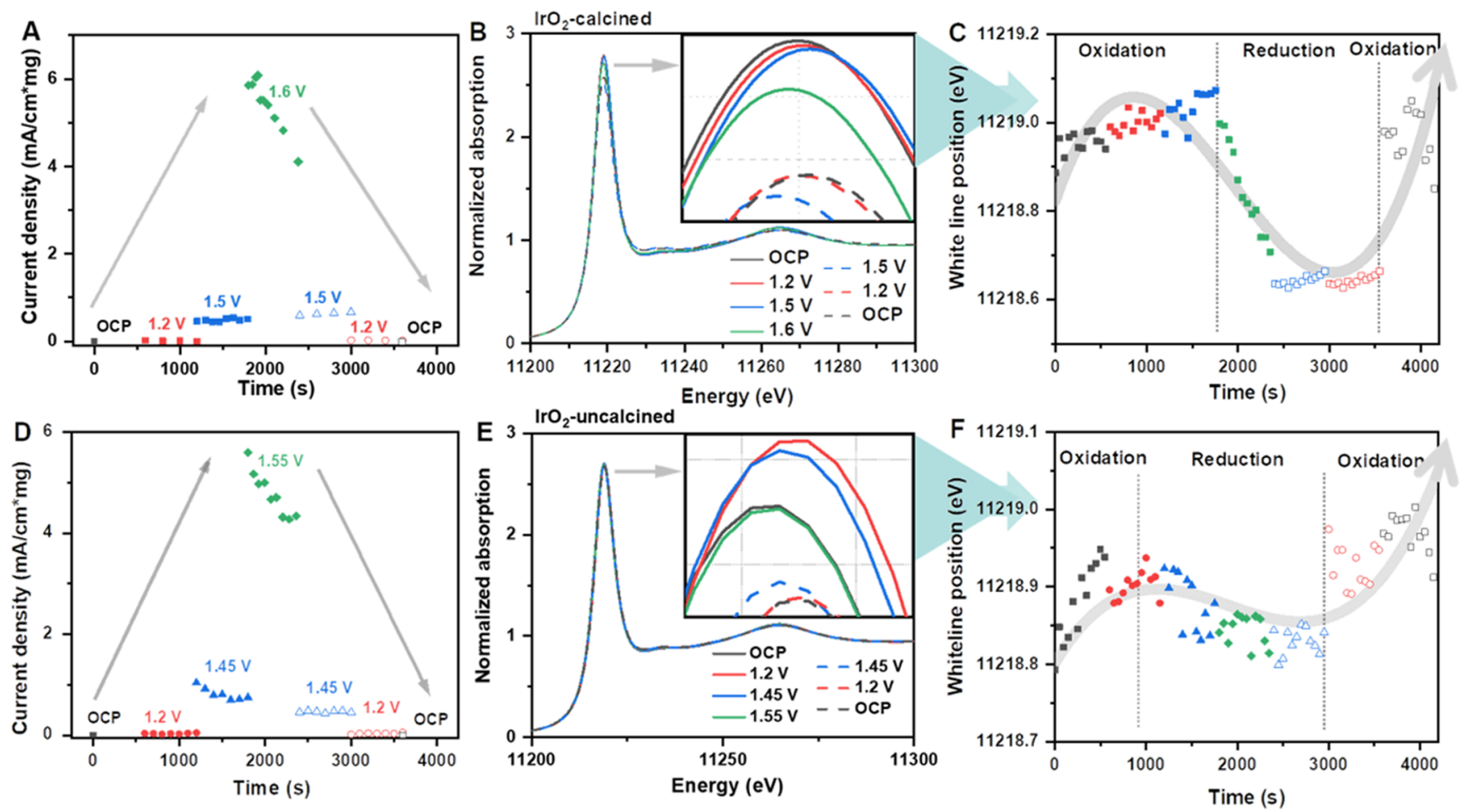

Figure 1. Electrochemical and XANES of $\mathrm{IrO}_{2}$ calcined $(\mathrm{A}-\mathrm{C})$ and uncalcined $(\mathrm{D}-\mathrm{F})$. First column: current vs measurement time of $\mathrm{IrO}_{2}$

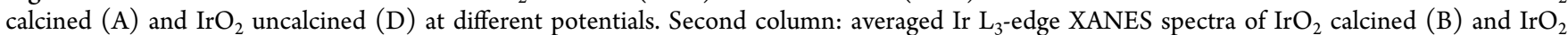
uncalcined (E). The inset of (B) and (E): the magnified scale of the white line peak region. Third column: the white line position (WLP) as a function of time and applied potential for $\mathrm{IrO}_{2}$ calcined (C) and $\mathrm{IrO}_{2}$ uncalcined (F). Additional measurements with smaller potential step increments of about $20 \mathrm{mV}$ (Figure S10) show that the observed change of the WLP is a continuous process and related to modifications of the applied potential. 


\section{IrO $\mathrm{H}_{2}$ calcined}
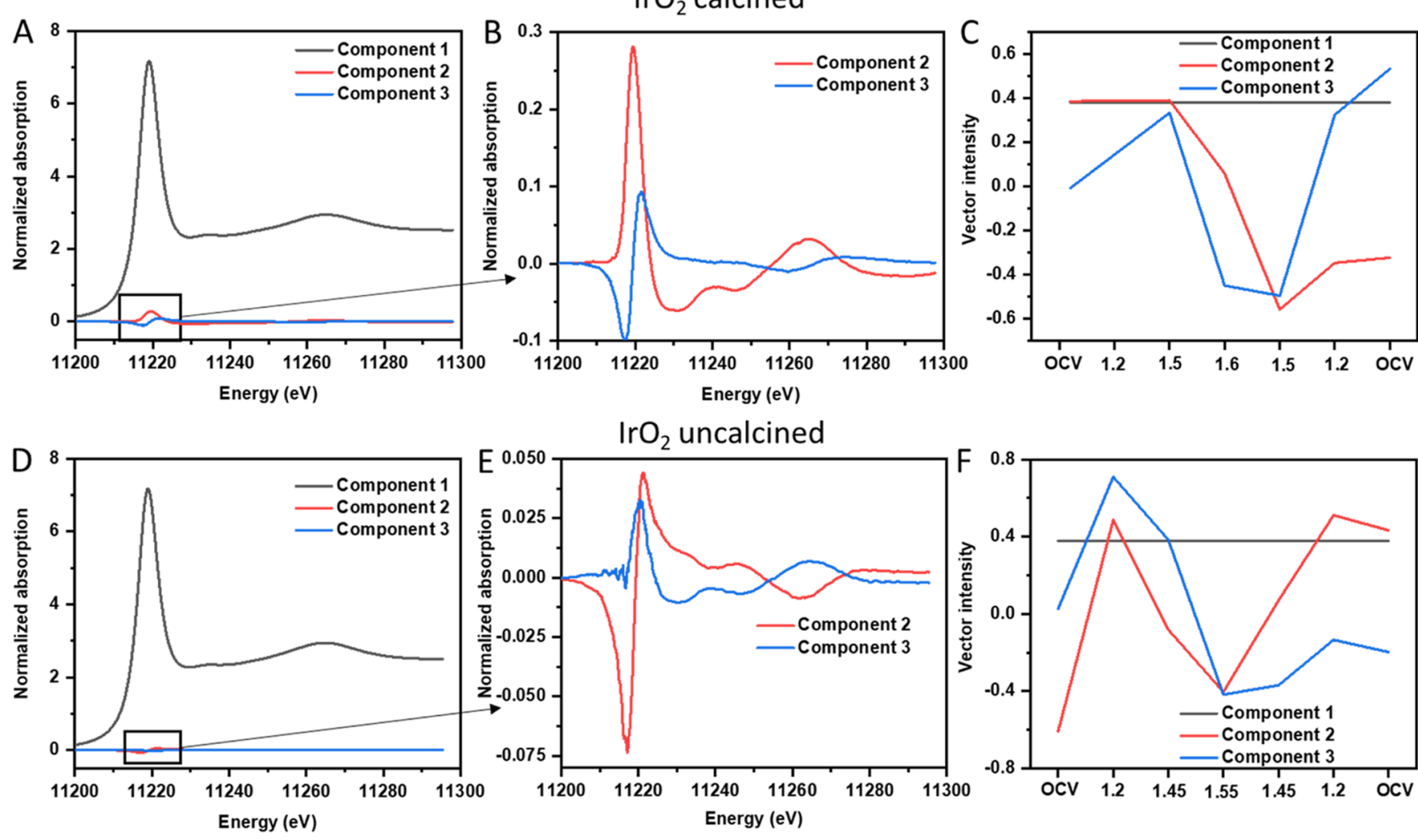

Figure 2. Principal component analysis of the data sets of $\mathrm{IrO}_{2}$ calcined $(\mathrm{A}-\mathrm{C})$ and $\mathrm{IrO}_{2}$ uncalcined $(\mathrm{D}-\mathrm{F})$ during stable potentials. The single graphs show the different components at different magnifications of $\mathrm{IrO}_{2}$ calcined $(\mathrm{A}-\mathrm{C})$ and $\mathrm{IrO}_{2}$ uncalcined $(\mathrm{D}-\mathrm{F})$, and the contribution of these components at different potentials $(\mathrm{C}, \mathrm{F})$.

this respect, the use of quick-XAS was crucial; the advantage over conventional XAS during the OER at high potentials is shown in Scheme S2. The insets in Figure 1B,E show a magnification of the white line peak position. During the change from low to high potential, a decrease in the white line height as well as a shift in the white line position can be observed. This shift is partially reversible and returns to its initial state after the working potential was decreased. Such a trend in the white line position was found for both samples, which strongly suggests that this trend is caused by a phenomenon unrelated to the degree of calcination of the sample.

For further understanding, Figure 1C,F shows the peak position of the working potential-dependent white line for calcined and uncalcined $\mathrm{IrO}_{2}$, respectively. For $\mathrm{IrO}_{2}$ calcined, an upward shift to more positive values is observable when changing the potential from OCP over 1.2 to $1.5 \mathrm{~V}$. This is attributed to the oxidation of the catalyst due to the oxidative current as well as coverage of the surface with oxygen. ${ }^{14}$ However, at $1.6 \mathrm{~V}\left(\mathrm{IrO}_{2}\right.$ calcined) and $1.55 \mathrm{~V}\left(\mathrm{IrO}_{2}\right.$ uncalcined), a significant shift of the white line position to lower energies was observed. This shift reversed when the potential was decreased again to 1.5 and $1.2 \mathrm{~V}$ for the calcined and uncalcined samples, respectively. The shift of the white line to lower energies can be traced back to an increase in the electronic density of Ir and/or reduction. This redox change at higher potentials is important to note since mostly an increase of the Ir oxidation state at applied OER potentials was observed, which are also highly oxidizing conditions. ${ }^{30-33,49}$ However, the applied potentials used here are also higher than in these previous studies.
Besides a shift in the white line position, we observed a change in the white line height, which seemed to change independently of the former, Figure 1B,E. To check whether two independent spectral changes and thus two distinct chemical variations were taking place, we applied principal component analysis (PCA), which is a common method for the analysis of XAS data sets ${ }^{50-52}$ to mathematically separate these components for further identification. (For a further description of the concept of PCA, refer to the ESI or the pertinent literature.)

Using principal component analysis, we extracted three components, which relate to two unique spectral changes in the structure of the $\mathrm{IrO}_{2}$ upon change of the potential. Three dominant principal components (PCs) were identified as representative of the experimental XANES spectra; the remaining components were assigned to noise and, therefore, neglected. PCA was applied to the XAS data sets of Figure $1 \mathrm{~B}, \mathrm{E}$ for $\mathrm{IrO}_{2}$ calcined and $\mathrm{IrO}_{2}$ uncalcined; i.e., the spectra recorded at stable potentials (potential steps at OCP, $1.2 \mathrm{~V}$ as well as at the low and high OER with holding the voltage for $10 \mathrm{~min}$ ). We focus on the first three components, Figure 2A,D. The first principal component of the two data sets of the two samples represents the strongest contribution, which can be ascribed to the unchanging background common to each sample in the stack. This is mostly related to the nonsurface atoms of the particles and, therefore, represents a nonchanging component. The second and third principal components contribute (lower part of both figures) with much lower intensity. For better visibility, these smaller contributions are shown in Figure 2B,E. Component 3 of $\mathrm{IrO}_{2}$ calcined as well as component 2 of $\mathrm{IrO}_{2}$ uncalcined clearly resemble the same 

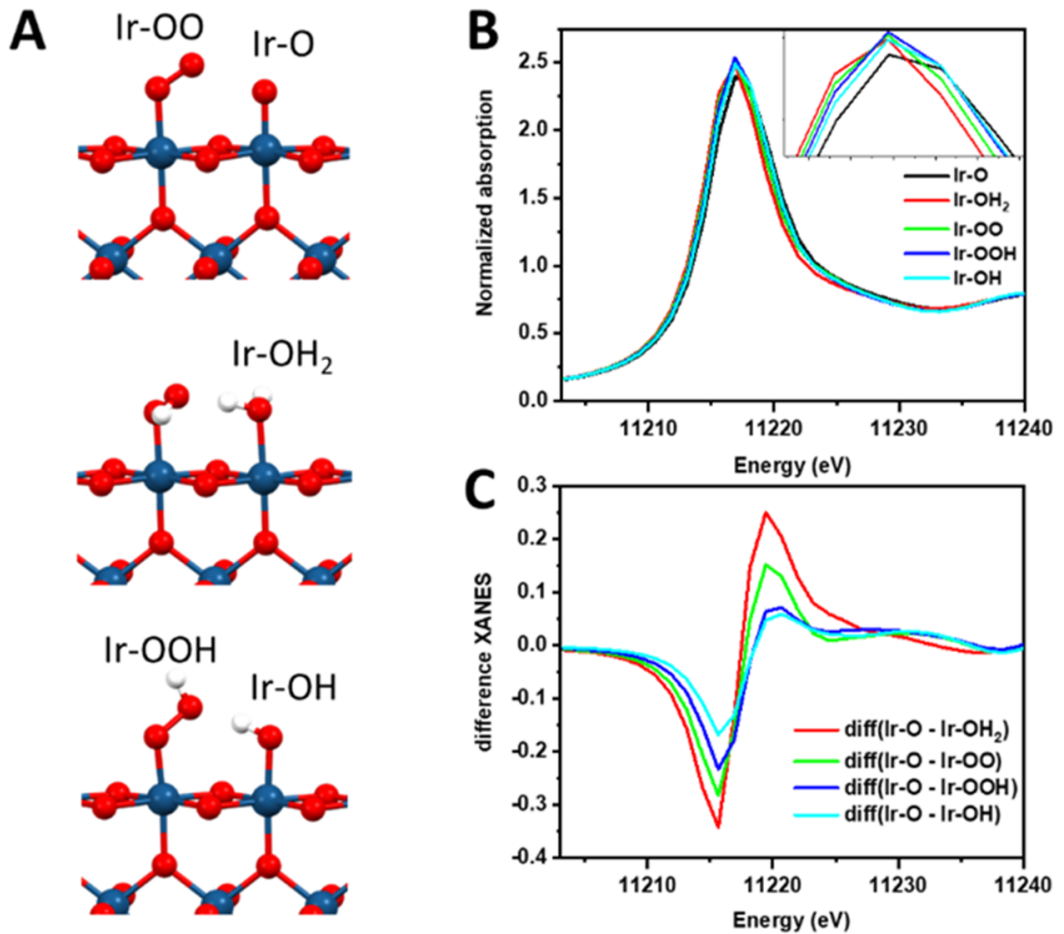

Figure 3. (A) Models of $\operatorname{Ir}_{\text {CUS }}$ sites on $\operatorname{IrO}_{2}(110)$ with ligands, optimized by DFT, from ref 11. (B) XANES calculations of structures from (A) using FEFF9, as well as difference spectra (C) between the native oxo species and the others: aqua, peroxo, hydroperoxo, and hydroxo species.

pattern. When comparing the raw XANES spectra at different potentials, the profile modifications coincide with the shifts in the white line peak positions (Figure 1C); therefore, we assign this characteristic shape as a "white line position shift" (WLPS). Analogously, component 2 of $\mathrm{IrO}_{2}$ calcined and component 3 of $\mathrm{IrO}_{2}$ uncalcined present a similar shape, which suggests that they are of a similar origin for both catalysts. In the raw XANES spectra, these components were matched with the change in the height of the white line at different potentials. Therefore, we assign this component as a "white line height decrease" (WLHD). Figure 2C,F shows the relative contribution or vector intensity, respectively, of these three components at the applied potentials tested. While component 1 remained unchanged throughout the whole measurements, components 2 and 3 changed distinctively across the potential profiles employed, reaching a peak in intensity at the highest potential values. This clearly correlates with the increased contribution of these components to modifications in the catalyst structure under OER potential conditions.

Since PCA only provides us the number and type of spectral variations, additionally, difference spectra were calculated (Figure S11A,B). The resulting shapes show a striking similarity to the calculated PCs. We note that the components appear in the difference spectra as a superposition and that it is not possible to separate them as in PCA. Therefore, to further confirm our interpretation, multivariate curve resolutionalternating least square (MCR-ALS) analysis was performed (Figure S11C-F). Here, a combined spectrum was calculated by averaging the three pure spectra, which were calculated by MCR-ALS. By subtracting the pure spectra from the related combined spectra, difference spectra were calculated (Figure S11D,F), which indicate the spectral changes. The shapes of these spectra are similar to the shape of the PCA components. Since MCR-ALS was bound to be bigger than zero, some components appear double and mirrored. These calculations further confirm that the PCA components in this case can obviously be related to real existing chemical species.

For a qualitative interpretation of the obtained PCs, we simulated XANES spectra using the FEFF9 code on known Ir surface species active for the OER (details, cf. SI). PCs 2 and 3 represent the changes in the spectra as exerted potentials are modified, i.e., they can be expressed as differences between the XANES at the respective potentials. The WLPS represents a shift in the white line without changing its intensity, which is observed when the effective surface Ir charge is modified in the presence of surface ligands without changing the overall crystalline structure of $\mathrm{IrO}_{2}$. We therefore used DFT-optimized structures of $\operatorname{Ir}_{\text {CUS }}$ (coordinately unsaturated sites) intermediates during the AEM from ref 11 as an input for simulating XANES spectra relevant to describe the WLPS: $\operatorname{Ir}_{\mathrm{CUS}}$ (coordinated unsaturated site) without ligands, $\operatorname{Ir}_{\mathrm{CUS}}-\mathrm{O}$, $\mathrm{Ir}_{\mathrm{CUS}}-\mathrm{OH}, \mathrm{Ir}_{\mathrm{CUS}}-\mathrm{OOH}$, and $\mathrm{Ir}_{\mathrm{CUS}}-\mathrm{OH}_{2}$ (Figure $3 \mathrm{~A}$ ). Comparison of the experimentally determined WLPS component to the calculated XANES in Figure 3B,C confirmed that this component was due to functionalization of the $\mathrm{IrO}_{2}$ surface with either of the ligands acting as intermediates in the OER. Since all of the ligands cause the white line shift, it was not possible to identify exactly which of the ligands was present. However, all of these components $\left(\mathrm{Ir}_{\mathrm{CUS}}-\mathrm{O}, \mathrm{Ir}_{\mathrm{CUS}}-\right.$ $\mathrm{OH}, \mathrm{Ir}_{\mathrm{CUS}}-\mathrm{OOH}$, and $\mathrm{Ir}_{\mathrm{CUS}}-\mathrm{OH}_{2}$ ) are proposed intermediates of the AEM, ${ }^{10,11}$ which indicates that the WLPS is likely related to the formation of oxygen by an adsorbate evolution mechanism.

The WLHD includes both a change in the white line intensity and the appearance of spectral features at higher energies. These are ascribed here to a transformation of $\mathrm{IrO}_{2}$ to the one containing a stronger $\mathrm{Ir}-\mathrm{Ir}$ interaction (e.g., typical for Ir metallic), as supported by EXAFS spectra analysis (vide infra). In the first approximation, we have expressed the WLHD as the difference spectra between $\mathrm{IrO}_{2}$ and face- 

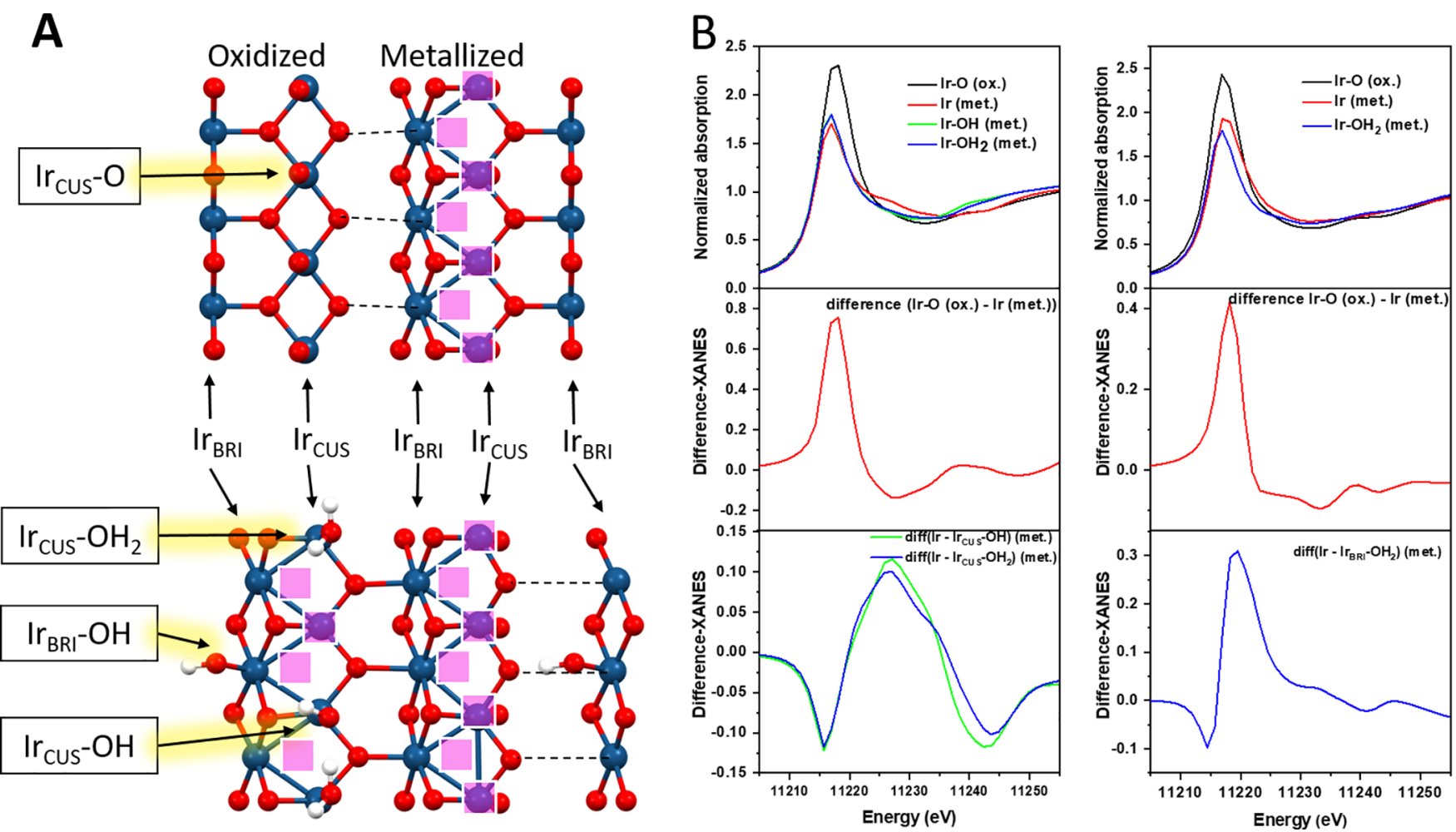

Figure 4. (A) Models of $\operatorname{Ir}_{\mathrm{CUS}}$ and $\mathrm{Ir}_{\mathrm{BRI}}$ sites on $\operatorname{IrO}_{2}(110)$, native oxidized and metalized after the removal of surface oxygen, additionally functionalized by aqua and hydroxo ligands, optimized by DFT. Pink squares indicate oxygen vacancies and dashed lines indicate broken Ir-O bonds. (B) XANES calculations of structures from (A) using FEFF9, as well as difference spectra between the native oxo species and the metalized, as well as the metalized with and without aqua and hydroxo ligands.
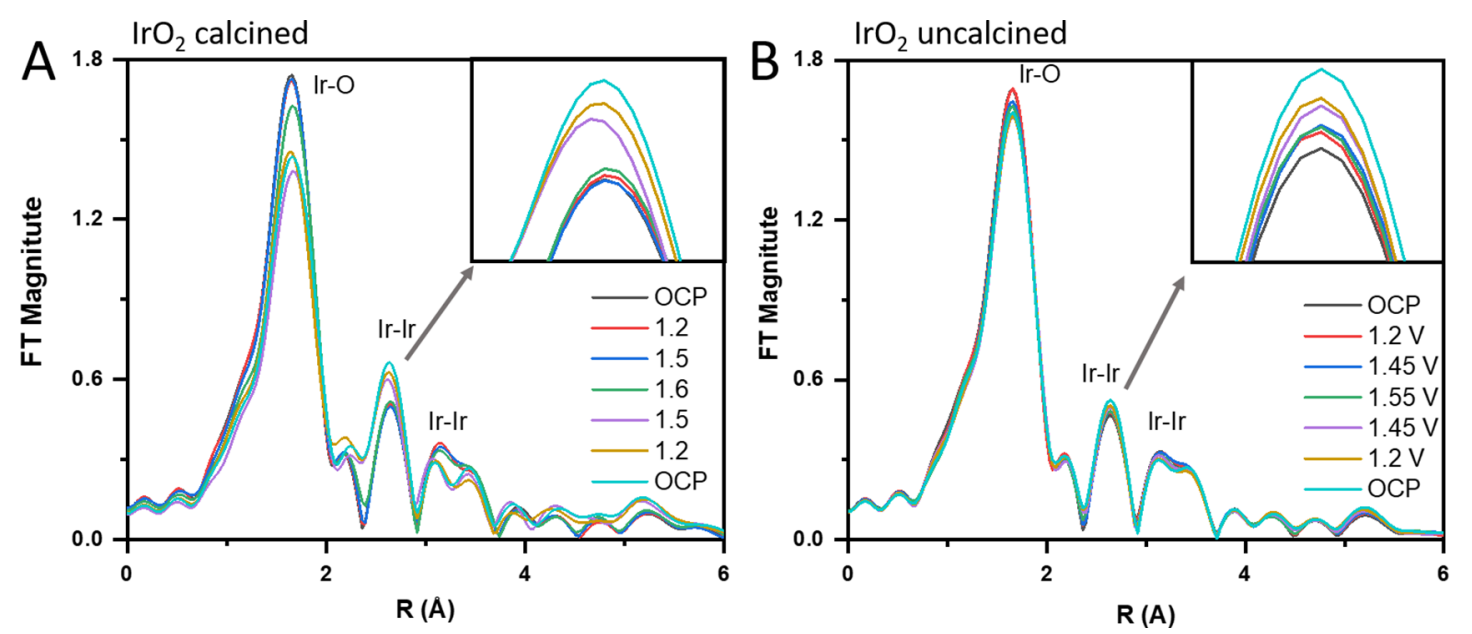

Figure 5. Fourier-transform EXAFS spectra of $\mathrm{IrO}_{2}$ calcined and $\mathrm{IrO}_{2}$ uncalcined during stable potential measurements.

centered cubic (fcc)-Ir, see Figure 4A. However, to achieve more representative surfaces, we employed DFT to optimize an $\mathrm{IrO}_{2}(110)$ surface geometry after consequent removing of 1-3 $\mathrm{O}_{\mathrm{CUS}}-\mathrm{O}_{\text {lat }}$ couples. This resulted in direct $\mathrm{Ir}-\mathrm{Ir}$ interactions with interatomic distances corresponding to those of metal-like Ir, Figure 4B.

Comparison of the WLHD component with calculated XANES suggests that oxidized $\mathrm{IrO}_{2}$ was partially reduced to domains where direct $\mathrm{Ir}-\mathrm{Ir}$ bonding occurred. It is noteworthy that a reduction of only a small fraction of $\mathrm{Ir}$ within an $\mathrm{IrO}_{2}$ matrix occurred, characterized by a decrease of the white line intensity but no shift of the white line position (the shift belongs strictly to the other principal component). This is seen in a continuous onset of the main maximum of the differenceXANES (Figure 4B), followed by a broad negative feature. If the reduction had caused the formation of bulk fcc-Ir, a simultaneous shift to lower energies would have been observed in the XANES, and the main maximum in the differenceXANES would have been preceded by a sharp minimum, see the difference between $\mathrm{IrO}_{2}$ and fcc-Ir in Figure S11G. We conclude that the observed metallization occurred locally in the $\mathrm{IrO}_{2}$ particles due to the stronger $\mathrm{Ir}-\mathrm{Ir}$ interaction and is not a separate metallic phase.

The Fourier-transform EXAFS spectra of calcined and uncalcined $\mathrm{IrO}_{2}$ during the stable potential measurements, which are presented in Figure 1, are shown in Figure 5. As 


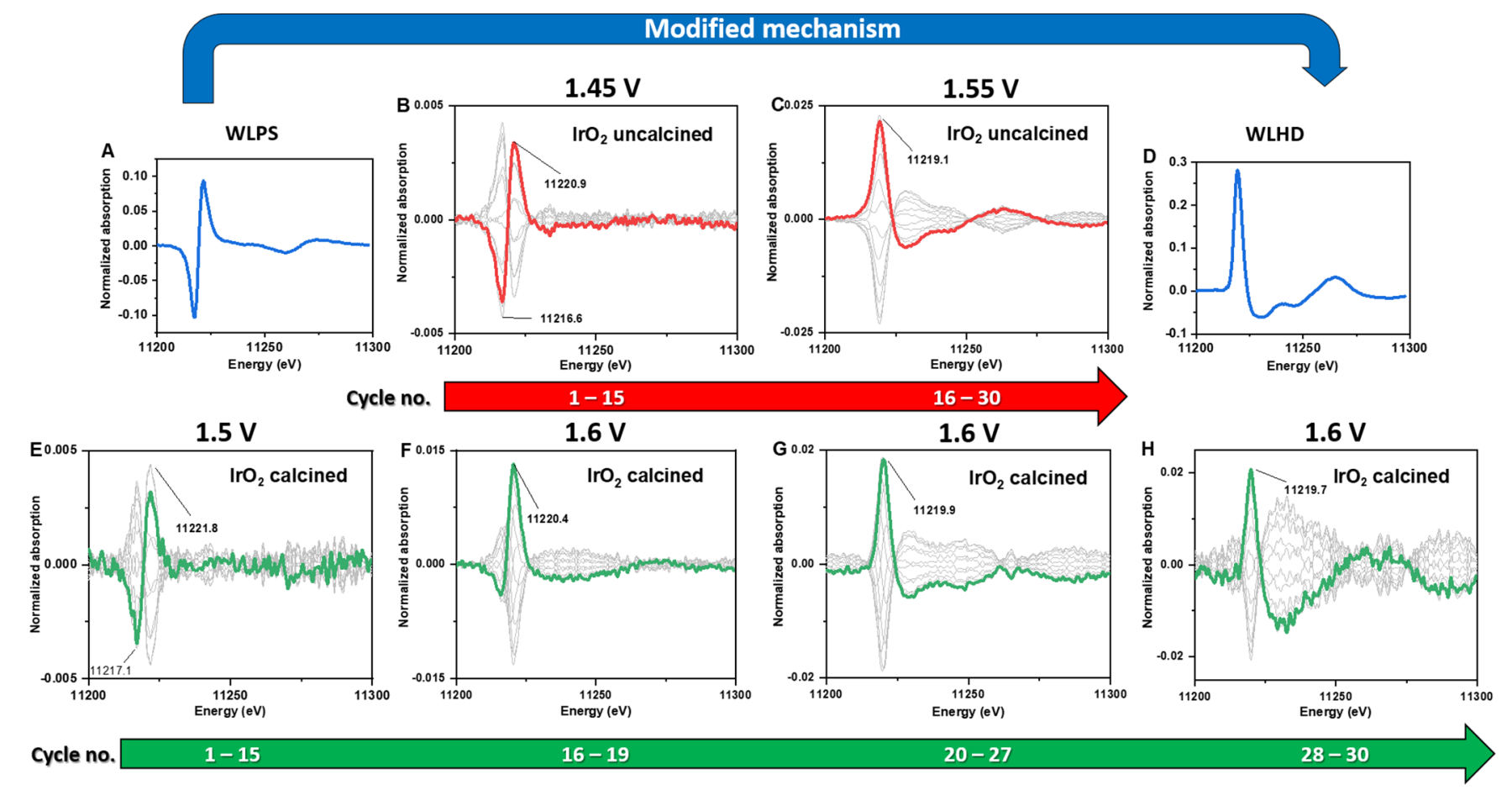

Figure 6. Changes of the catalysts during MES. Phase-resolved spectra of $\mathrm{IrO}_{2}$ uncalcined (B, C, red) and calcined (E-H, green). The measurement consisted of 15 cycles of $2 \mathrm{~min}$ at $1.2 \mathrm{~V}$ and $2 \mathrm{~min}$ at $1.6 \mathrm{~V}$ ( $1.55 \mathrm{~V}$ for $\mathrm{IrO}_{2}$ uncalcined). For comparison, PCA components were added (A, D, blue). The arrows indicate the measurement cycles out of which the MES was generated. The gray lines present the phase-resolved spectra, with one line per graph highlighted in green or red to emphasize the shape.

mentioned earlier, three main backscattering contributions are observable: an oxygen shell at about $1.8 \AA$, a metal-like $\mathrm{Ir}-\mathrm{Ir}$ shell contribution ( $\mathrm{Ir}-\mathrm{Ir}$ distance along the $c$-axis) at $2.5 \AA$, and an oxidic Ir-Ir contribution at about $3.2 \AA$ (distance between the body center Ir and the tetrahedral vertex Ir). ${ }^{53} \mathrm{~A}$ strong decrease of the oxygen shell contribution is observed for the calcined $\mathrm{IrO}_{2}$ sample. A similar decrease in intensity is seen for the longer oxidic Ir-Ir shell, while the shorter Ir-Ir contribution increases. This indicates a strong rearrangement within the structure during the electrochemical processes. In contrast, only minor changes can be observed in the $\mathrm{IrO}_{2}$ uncalcined sample (Figure $3 \mathrm{~B}$ ). This is surprising since it is widely accepted that uncalcined $\mathrm{IrO}_{2}$ is less stable compared to calcined $\mathrm{IrO}_{2}$ and should therefore undergo greater changes. However, this might indicate that the stability of $\mathrm{IrO}_{2}$ calcined is actually related to a rearrangement during the OER, which could be associated with higher dissolution stability.

Modulation Excitation Spectroscopy. Modulation excitation spectroscopy (MES) measurements were performed to further investigate the changes seen above during the OER. MES is a powerful method to resolve reversible dynamic species; for example, in the case of a two-step reaction $\mathrm{X} \rightarrow \mathrm{Y}$ $\rightarrow \mathrm{Z}$, the characteristic signals of the different species will have maximum amplitudes at different phase angles, and a thorough analysis can provide differentiation of pathways and lifetimes of the active species during the modulation period. ${ }^{27}$ In MES, alternating OER potential conditions are employed to fully resolve the observed surface rearrangements within the $\mathrm{IrO}_{2}$ structures. Since PCA represents a purely mathematical method, this allows comparing the above-observed results with experimental data. Therefore, here, the pre-OER and OER potentials of 1.2 and $1.6 \mathrm{~V}(1.55 \mathrm{~V}$ for the uncalcined sample) were applied alternately, with each potential held for 2 min. After 15 cycles, the OER potential was increased and repeated for 15 cycles (see Table 1 for values). The resulting time-resolved spectra show no discernible differences (Figures S12 and S13).

After demodulation of the spectra, however, the phaseresolved graphs (Figure 6) show clear changes depending on the phase angle. To clarify the directions of the phase change, the spectra for each measurement can be found in the SI (Figures S14-S16). For instance, in the time-resolved spectra of uncalcined $\mathrm{IrO}_{2}$ (Figure S13), only small changes between the different spectra can be seen. However, after demodulation (MES1, Figure S15), changes in the spectra became visible. These changes manifest in a pattern of two peaks whose intensity changes symmetrically to the phase angle (from 0 to $360^{\circ}$ ). After increasing the applied potential (MES2, Figure S15), the pattern changed to only one peak. Again, the intensity changes in relation to the phase angle. Figure $6 \mathrm{~B}, \mathrm{C}$ shows the time phase-resolved spectra of uncalcined $\mathrm{IrO}_{2}$, separately for the first 15 cycles and the second 15 cycles. Figure $6 \mathrm{E}-\mathrm{H}$ shows the time-resolved spectra of calcined $\mathrm{IrO}_{2}$, also divided into different batch cycles, indicated by the green arrow. For comparison, the spectra of the two PCA components in Figure 6A,D were added.

XAS shows a change for the uncalcined $\mathrm{IrO}_{2}$ from a shape similar to the WLPS component to a shape more similar to the WLHD component when the potential is changed from 1.45 to $1.55 \mathrm{~V}$, Figure $6 \mathrm{~B}, \mathrm{C}$. We attributed this to a change in the mechanism caused by the increased potential, as further discussed below. The same change in the mechanism was observed for the calcined samples, as shown in Figure $6 \mathrm{E}-\mathrm{H}$. To further illustrate this gradual change, the spectra of the second set of 15 MES cycles for $\mathrm{IrO}_{2}$ calcined were split into three separate plots: from the 16th to the 19th cycle (Figure 
$6 \mathrm{~F}$ ), then from the 20th to the 27th cycle (Figure $6 \mathrm{G}$ ), and from the 28th to the 30th cycle (Figure $6 \mathrm{H}$ ). At the pre-OER and at lower OER potentials $(1.5 \mathrm{~V})$, the phase-resolved MES show the distinct WLPS component. Note that one has to be careful with the interpretation of spectra, Figure $6 \mathrm{~F}-\mathrm{H}$, as the structure changes and is not reversible. Nevertheless, it clearly illustrates how the structure evolves. After applying a higher potential $(1.6 \mathrm{~V})$, a slow change in the mechanism is observed. As already mentioned, PCA is only a mathematical method. However, the fact that the same components also appear in the demodulated spectra and the comparison with MCR-ALS in the previous section suggests that these mathematical components are equivalent in this experiment and both represent spectral changes assigned to the same chemical transformations.

Electrochemical Behavior during the MES Protocol. To investigate the electrochemical stability during these changes in MES, electrochemical dissolution measurements were performed on pristine calcined $\mathrm{IrO}_{2}$ and uncalcined samples using on-line ICP-MS (Figure 7) for the MES

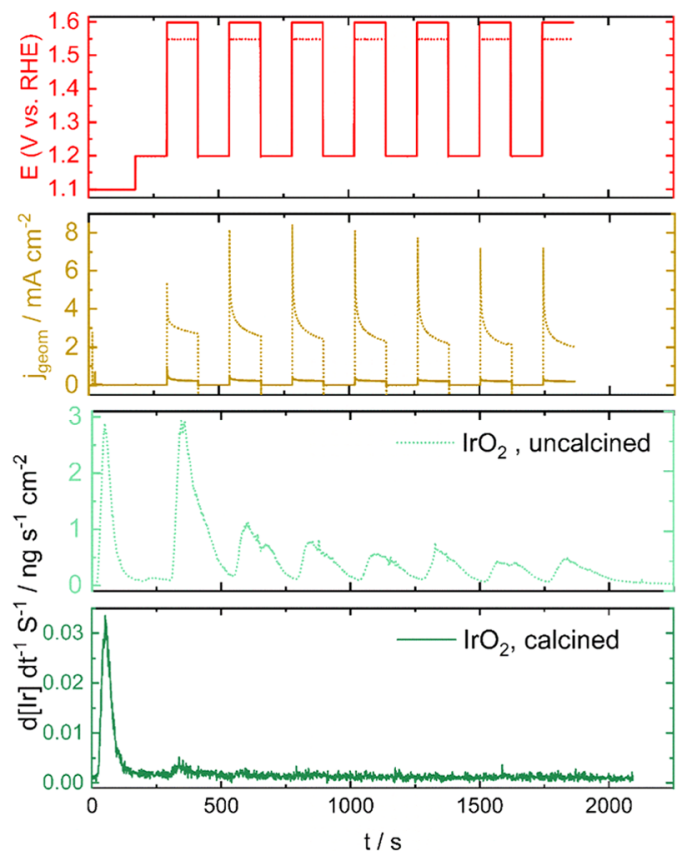

Figure 7. Online Ir dissolution data obtained during the MES potentiostatic pre-OER/"high OER" on/off protocol. Short-dotted lines in the $E-t$ and $j-t$ graphs represent the potential profile and resulting geometric current densities obtained for the $\mathrm{IrO}_{2}$ uncalcined sample.

protocol alternating pre-OER potentials of $1.2 \mathrm{~V}$ to higher OER potentials for seven cycles $\left(\mathrm{IrO}_{2}\right.$ calcined: $1.6 \mathrm{~V}, \mathrm{IrO}_{2}$ calcined: $1.55 \mathrm{~V}$ ). The recorded dissolution rates showed a selective Ir dissolution under OER potentials, where integrated Ir dissolution values per OER potential hold were 3 orders of magnitude higher for uncalcined than for calcined $\mathrm{IrO}_{2}$ FSP catalysts. This is in good agreement with previous reports that correlated higher stabilities under OER operation for $\mathrm{IrO}_{x^{-}}$ based materials with higher crystallinities induced by thermal treatment. $^{48,54,55}$ Interestingly, a steady-state in the Ir dissolution rates after the fifth MES cycle was found, regardless of the degree of calcination, which can be further understood by our recently proposed dissolution stability benchmarking metric: the stability number ( $S$-number, details in ref 9 , cf. also Figure S17).

Effect of Catalyst Aging in the MES Phase-Resolved Spectra. In the case of the operando XAS, PCA analysis was performed again on the XANES spectra of the now MES-aged $\mathrm{IrO}_{2}$ calcined and uncalcined samples under "steady-state" potentiostatic hold conditions (Figure 8), for the same electrochemical protocol as above, Figure 1. Surprisingly, both the WLHD component and the WLPS component are still present during these measurements, as can be seen in Figure $8 \mathrm{~B}$, for the aged calcined $\mathrm{IrO}_{2}$ as well as in Figure $8 \mathrm{E}$ for the aged uncalcined $\mathrm{IrO}_{2}$. This indicates that the observed stabilization with the gradual disappearance of the WLPS component occurs not only under the experimental conditions found during MES but also after MES measurements recorded under stable potentials.

To further evaluate the impact of electrochemical prehistory in the XAS spectral features, Figure 9 shows the EXAFS spectra of fresh $\mathrm{IrO}_{2}$ calcined and $\mathrm{IrO}_{2}$ uncalcined during an OCP and after several different measurement steps. To simplify the comparison, the experimental spectra of fcc-Ir have been added to each figure (labeled in blue). Figure 9A shows fresh $\mathrm{IrO}_{2}$ calcined and $\mathrm{IrO}_{2}$ uncalcined without electrochemical prehistory. The fcc-Ir crystal structure of densely packed Ir atoms, with an average $\mathrm{Ir}-\mathrm{Ir}$ distance of about $2.7 \AA$, shows a peak at this distance in the blue spectra. Since the $\mathrm{Ir}-\mathrm{Ir}$ distance in Iridium oxide is longer $(3.2 \AA)$, there is only a small contribution at $2.7 \AA$ in the fresh calcined and uncalcined $\mathrm{IrO}_{2}$ samples in Figure 9A, consistent with XRD.

In Figure 9B, calcined and uncalcined $\mathrm{IrO}_{2}$ are shown after undergoing electrochemical aging under MES conditions. In contrast to the previous graph, both samples show metal-like Ir-Ir scattering $(2.7 \AA)$ as in fcc-Ir, shown for comparison. This might indicate a partially irreversible increased $\mathrm{Ir}-\mathrm{Ir}$ interaction. Since it was shown that during the second MES (1.2/1.55 V for uncalcined and $1.2 / 1.6 \mathrm{~V}$ for calcined), the WLHD component dominantly described the changes in the XANES spectra; the corresponding increase in the direct Ir-Ir binding interactions was most likely caused by a mechanism that promotes the formation of oxygen-deficient metal-like sites. Surprisingly, these contributions appear to become weaker after the aged samples pass through the measurements at stable potentials (Figure 9C), showing that the surface oxidation state of $\mathrm{Ir}-\mathrm{Ir}$ was partly reversed.

In summary, the WLHD component and the direct $\mathrm{Ir}-\mathrm{Ir}$ interaction were dominant when immediately changing between $1.2 \mathrm{~V}$ and the high OER potentials as in the second MES. On the other hand, the WLPS component was present in the first MES when changing from $1.2 \mathrm{~V}$ and low OER potentials as in the stable potential protocol, reversing the surface changes at the same time. The relationship between these observations is addressed in the Discussion.

\section{DISCUSSION}

Chemical Assignment of XANES Features. By comparing the FEFF9 with the PCA results, the WLHD component cannot be unambiguously assigned to a specific phenomenon, as there are several components that would fit the observed spectral shape. Among them, the calculated spectra that would fit are the adsorption of $\mathrm{O}, \mathrm{OH}$, and $\mathrm{OOH}$ species onto an $\mathrm{IrO}_{2}$ surface. Given the nature of the OER operating under the AEM, one would expect most of these components to be present as reaction intermediates. Therefore, it is most likely 

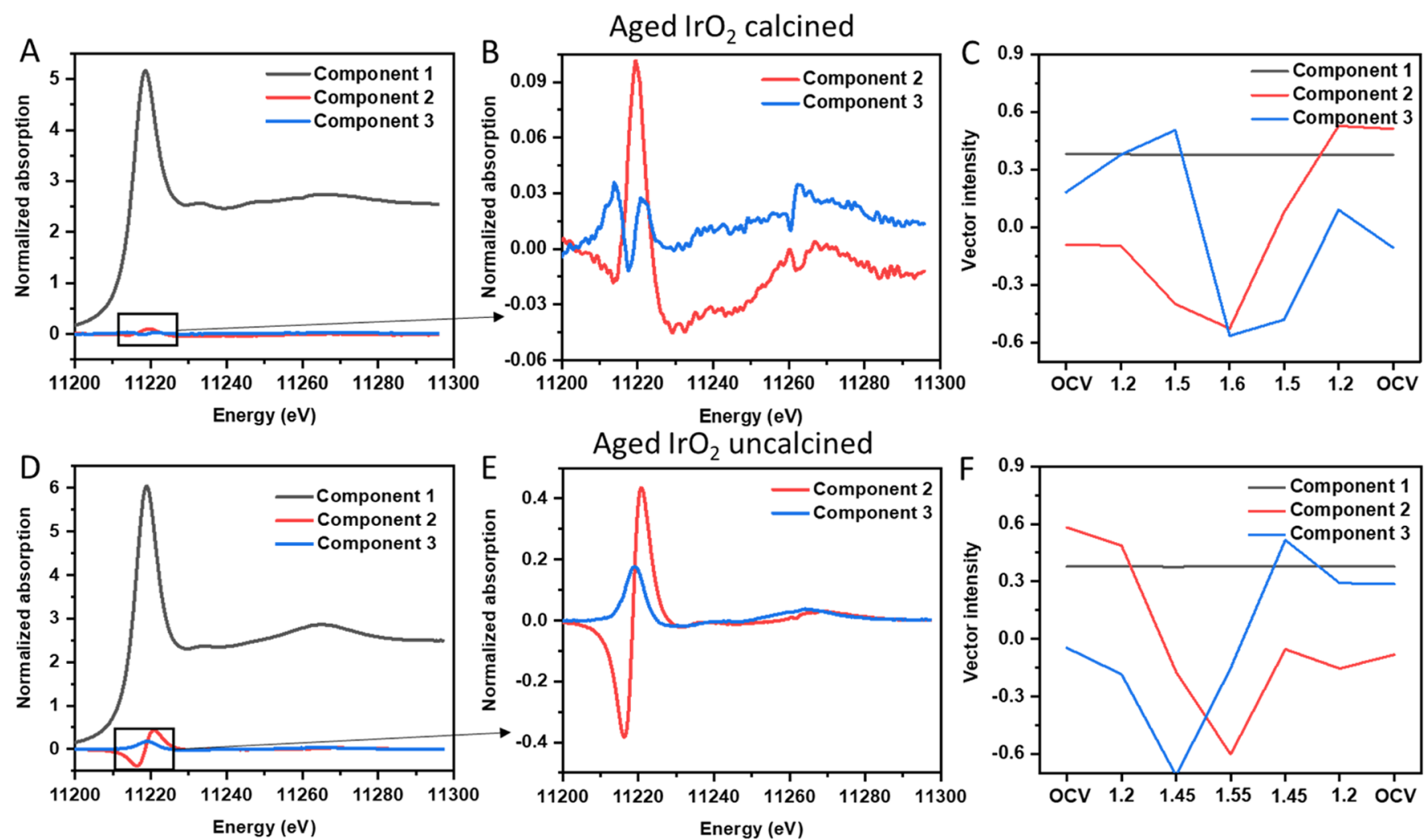

Figure 8. PCA analysis of aged $\mathrm{IrO}_{2}$ calcined $(\mathrm{A}-\mathrm{C})$ and aged $\mathrm{IrO}_{2}$ uncalcined (D-F) during stable potentials after MES measurements. The single graphs show the different components in different magnifications of $\mathrm{IrO}_{2}$ calcined (A, B) and $\mathrm{IrO}_{2}$ uncalcined (D, E), and the contribution of these components at different potentials $(\mathrm{C}, \mathrm{F})$.

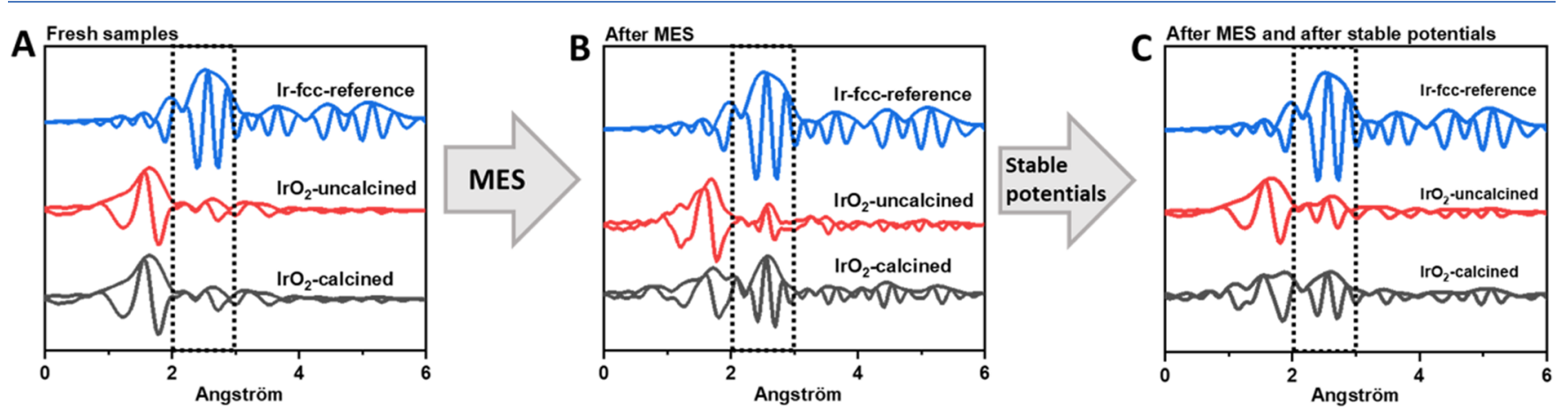

Figure 9. Increased metal-like $\mathrm{Ir}-\mathrm{Ir}$ contribution. EXAFS spectra of $\mathrm{IrO}_{2}$ calcined and $\mathrm{IrO}_{2}$ uncalcined during OCP of fresh samples (A), after MES (B), and after MES and stable potentials (C).

that the resulting spectra present a contribution of various of these components, which could therefore be assigned to the AEM. There are several possible explanations for the WLPS. Since FEFF9 calculations and EXAFS results suggest an increased Ir-Ir interaction, the corresponding mechanism would have to involve removal of oxygen from the lattice between two Ir atoms. On the one hand, this could indicate a lattice oxygen mechanism (LOM), i.e., lattice oxygen takes place in the reaction. The observation in the MES could then be explained by a change of the mechanism from LOM/AEM to LOM only, by increasing the applied potential above $1.5 \mathrm{~V}$, and the increased Ir-Ir contribution as a resulting effect of the removal of lattice oxygen. The LOM and the AEM are thought to have different activation energies. Given that PCA calculations showed that both components occur simulta- neously at lower OER potentials, another explanation could be a modified AEM, which we propose in Figure 10.

The conventional AEM involves four proton-coupled electron transfer steps $(2)-(5) .^{60}$ Since DFT results consistently assume a stable oxygen saturated bridging (BRI) site configuration during the OER, the reactions take place at the coordinately unsaturated (CUS) site. $^{56-59}$ In these considerations, it is assumed that the water adsorption in reaction step (1) is coupled with that of the OER in step (5). However, we propose here that this additional water adsorption step has to be considered separately, as it is a purely chemical and, therefore, a potential independent step with a relevant impact on the reaction kinetics. ${ }^{60}$ Furthermore, DFT studies identified reaction step (4) as the electrochemically limiting step. ${ }^{15,56,57,59}$ Based on these assumptions, the formation of oxygen vacancies can occur via reaction step (6) 

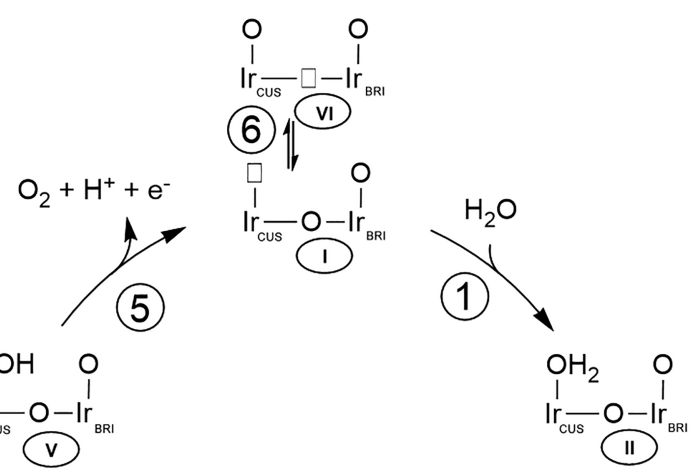

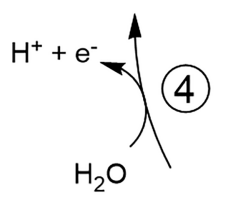
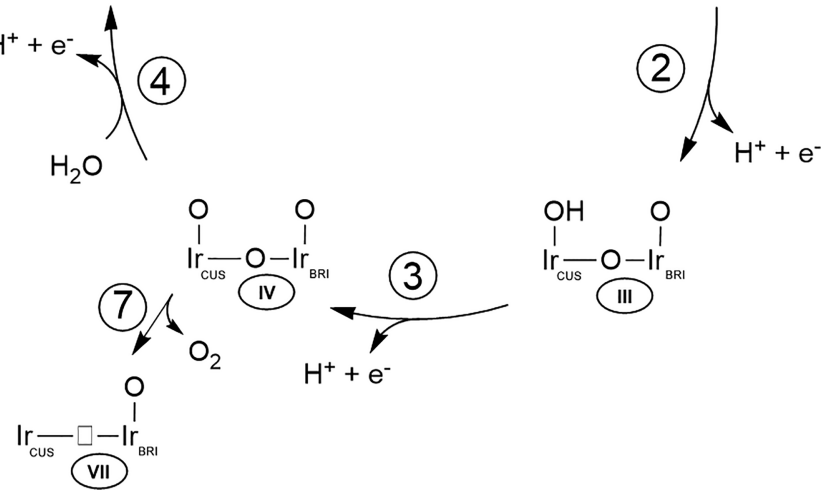

Figure 10. Proposed scheme for the AEM is motivated from ref 60 and extended by two steps containing the removal of $\mathrm{O}$ from the lattice (step 7) to explain the observed behaviors.

alongside the saturation of the $\operatorname{Ir}_{\mathrm{CUS}}$ and via step (7) during irreversible oxygen evolution. Both reactions lead to a vacancy in the lattice, which may result in a closer interaction of $\operatorname{Ir}_{\mathrm{CUS}}$ and $\mathrm{Ir}_{\mathrm{BRI}}$, as reflected in the EXAFS spectra. Filling up the vacancies in the lattice is not necessarily needed to let the circle run again, as shown in the mechanistic scheme in Figure 10. Both formation pathways are assumed to proceed kinetically slow in comparison to the OER mechanism. Thus, the prolonged availability of species (I) and (IV) increases the kinetic rates for oxygen vacancy formation, regardless of whether the products are thermodynamically less preferred. This is particularly the case at high OER potentials, where large amounts of oxygen are produced and a greater number of species (I) and (IV) are available.

Metal-Like Ir-Ir Interaction and Catalyst Stabilization. As mentioned earlier, it is noteworthy that this increased $\mathrm{Ir}-\mathrm{Ir}$ interaction appears stronger in calcined $\mathrm{IrO}_{2}$. This might be caused by the more ordered structure of calcined $\mathrm{IrO}_{2}$, where the regular $\mathrm{Ir}-\mathrm{O}-\mathrm{Ir}$ structure benefits the formation of Ir-Ir after oxygen removal. Furthermore, this could also indicate that this increased $\mathrm{Ir}-\mathrm{Ir}$ interaction stabilizes the catalyst, which may be the reason for the increased dissolution stability in calcined OER electrocatalysts.

Since the current density during the measurement was approximately the same for both electrocatalysts, we exclude the possibility that the stronger Ir-Ir interaction in calcined $\mathrm{IrO}_{2}$ compared to uncalcined $\mathrm{IrO}_{2}$ is caused by the higher applied potential $\left(1.6 \mathrm{~V}\right.$ for $\mathrm{IrO}_{2}$ calcined, $1.55 \mathrm{~V}$ for $\mathrm{IrO}_{2}$ uncalcined). The change of the XANES components from the WLPS to WLHD shortly after the start of the second MES at high potential, together with a strong stabilization of both catalysts confirmed by ICP-MS, indicates that most catalytic centers, which otherwise tend to dissolve, are stabilized by the formation of $\mathrm{Ir}-\mathrm{Ir}$ interactions.

It is surprising that stabilization by the direct $\mathrm{Ir}-\mathrm{Ir}$ interaction was not observed earlier, as it seems to be a fundamental characteristic of $\mathrm{IrO}_{2}$ catalysts. As mentioned above, we attribute this to the absence of in situ XAS during the OER measurements at higher potentials. For instance, Siracusano et al. ${ }^{61}$ stated that oxygen is released from the catalyst lattice at high applied potentials, but this was not further investigated by in situ measurements. Other previous XAS investigations only observed oxidation of the catalyst, ${ }^{31-33,42}$ which is related to the lower OER potentials applied. Probably, mostly lower potentials were applied to avoid the interference of bubble formation at high OER potentials. As mentioned above, our solution here was to use quick-XAS and average out the random bubble evolution. Nevertheless, it would be rewarding to study its influence on the spectra in detail. Interestingly, Abbott et al. ${ }^{32}$ observed a reduction of $\mathrm{IrO}_{2}$ after cycling between 1.0 and $1.6 \mathrm{~V}$ with ex situ measurements. Without further investigation, they attributed this to a decrease of $\mathrm{Ir}^{4+}$ and an increase in $\mathrm{Ir}^{3+}$ species. We explain this phenomenon by the formation of the increased $\mathrm{Ir}-\mathrm{Ir}$ interaction due to the removal of oxygen from the lattice, and not all oxygen vacancies are filled up under these conditions.

Apparently, the increase in the Ir-Ir interaction appears to be much stronger during the MES than during stable potential measurements, although the same highest potential values (1.6 and $1.55 \mathrm{~V}$ ) are reached. Considering our observations above that reduction is only observed at high potentials, while oxidation at lower OER potentials, the MES protocol that only alternates between the high and no OER without applying low OER potentials could be prone to the reduction of the catalyst. In addition, the steps without oxygen evolution in the MES protocol might facilitate the formation of oxygen vacancies on the catalyst. In the EXAFS spectra in Figure 3A, the increased $\mathrm{Ir}-\mathrm{Ir}$ interaction is seen only when changing from 1.6 back to $1.5 \mathrm{~V}$. Likewise, there is a greater increase in the uncalcined sample from 1.55 to $1.45 \mathrm{~V}$, while there is no change at $1.55 \mathrm{~V}$ compared to prior $1.45 \mathrm{~V}$. Again, this trend is clearer in the calcined sample. This could be due to a structural change in the $\mathrm{Ir}-\mathrm{O}-\mathrm{Ir}$ structure that takes place at the higher OER potentials in the structure, releasing oxygen from the lattice. The formation of the Ir-Ir interaction then only proceeds after the reaction rate decreases and the lattice vacancy is not refilled with oxygen fast enough. Nevertheless, this vacancy formation leads to a more stable $\mathrm{IrO}_{2}$ catalyst. Oxygen labeling was used previously to investigate the electrochemical behavior of $\mathrm{IrO}_{2}$ during the OER. ${ }^{62,63}$ The results showed that an increased number of oxygen is released from the lattice with increasing potentials, although only for hydrous Ir oxide. ${ }^{62}$ However, due to the dynamicity of our measurement protocol, it is not possible to completely transfer the observations to our results and might vary depending on the operation conditions. Further $\mathrm{O}$ labeling investigations under a similar dynamic test protocol applied here could give deeper insights into these investigations in the future.

\section{CONCLUSIONS}

Conventional operando and ME-XAS measurements combined with in situ studies of Ir dissolution by ICP-MS and detailed analysis by PCA analysis, theoretical calculation of XANES spectra, and DFT calculation have been conducted on 
$\mathrm{IrO}_{2}$-catalyzed oxygen evolution to better understand the different mechanisms that occur during the OER at the various potentials. Operando XAS spectroscopy was utilized to study the OER under different protocols on calcined and uncalcined $\mathrm{IrO}_{2}$ on the $\mathrm{Ir} \mathrm{L}_{3}$-edge. This combination of several techniques presents a valuable approach for the thorough investigation of catalysts under dynamic working conditions. First, we measured the electrocatalysts under stable conditions with varying potentials. Using an optimized flow cell and rapid XAS measurements with signal averaging, the influence of bubble formation could be minimized. Principal component analysis allowed us to separate the spectra into different representative contributions and to quantify them as substantiated by MCRALS analysis. Difference spectra as well as FEFF9 calculations then enabled us to assign the various components to two different OER modes. Both modes were shown to take place in the uncalcined as well as in the calcined samples, and the difference in performance and dissolution stability stems from which mechanism is dominant in the electrocatalyst. In situ ICP-MS measurements showed a rapid stabilization of the catalyst when alternating switching between pre-OER and OER conditions. In combination with modulation excitation spectroscopy XAS, these could be assigned to a modification in the role of oxygen vacancies in the mechanism when switching from low to high OER potentials. This work has particular relevance for understanding the stabilization of OER catalysts under dynamic operation, as changes appearing under these conditions-especially changes in $\mathrm{Ir}-\mathrm{Ir}$ distances-are more dominant.

\section{ASSOCIATED CONTENT}

\section{(s) Supporting Information}

The Supporting Information is available free of charge at https://pubs.acs.org/doi/10.1021/acscatal.1c02074.

Additional experimental details; electrochemical measurements and electrocatalytic results; calculated white line position; edge jump; deviation and residue of the XAS spectra presented in the manuscript; extracted MCR-ALS spectra; and additional information on the stability number (PDF)

\section{AUTHOR INFORMATION}

\section{Corresponding Authors}

Alexey Boubnov - Institute for Chemical Technology and Polymer Chemistry and Institute of Catalysis Research and Technology, Karlsruhe Institute of Technology, 76131 Karlsruhe, Germany; Email: alexey.boubnov@kit.edu

Serhiy Cherevko - Helmholtz-Institute Erlangen-Nürnberg for Renewable Energy (IEK-11), Forschungszentrum Jülich GmbH, 91058 Erlangen, Germany; 이이.org/00000002-7188-4857; Email: s.cherevko@fz-juelich.de

Jan-Dierk Grunwaldt - Institute for Chemical Technology and Polymer Chemistry and Institute of Catalysis Research and Technology, Karlsruhe Institute of Technology, 76131 Karlsruhe, Germany; @ orcid.org/0000-0003-3606-0956; Email: grunwaldt@kit.edu

\section{Authors}

Steffen Czioska - Institute for Chemical Technology and Polymer Chemistry and Institute of Catalysis Research and Technology, Karlsruhe Institute of Technology, 76131 Karlsruhe, Germany
Daniel Escalera-López - Helmholtz-Institute ErlangenNürnberg for Renewable Energy (IEK-11), Forschungszentrum Jülich GmbH, 91058 Erlangen, Germany; ○ orcid.org/0000-0002-2001-9775

Janis Geppert - Institute for Applied MaterialsElectrochemical Technologies, Karlsruhe Institute of Technology, 76131 Karlsruhe, Germany

Alexandra Zagalskaya - Department of Chemical and Biomolecular Engineering, University of Nebraska-Lincoln, Lincoln, Nebraska 68588, United States; Nebraska Center for Materials and Nanoscience, University of Nebraska-Lincoln, Lincoln, Nebraska 68588, United States

Philipp Röse - Institute for Applied MaterialsElectrochemical Technologies, Karlsruhe Institute of Technology, 76131 Karlsruhe, Germany; 이이이.org/00000001-6591-7133

Erisa Saraçi - Institute for Chemical Technology and Polymer Chemistry and Institute of Catalysis Research and Technology, Karlsruhe Institute of Technology, 76131 Karlsruhe, Germany

Vitaly Alexandrov - Department of Chemical and Biomolecular Engineering, University of Nebraska-Lincoln, Lincoln, Nebraska 68588, United States; Nebraska Center for Materials and Nanoscience, University of Nebraska-Lincoln, Lincoln, Nebraska 68588, United States; () orcid.org/0000-0003-2063-6914

Ulrike Krewer - Institute for Applied MaterialsElectrochemical Technologies, Karlsruhe Institute of Technology, 76131 Karlsruhe, Germany; 이이.org/00000002-5984-5935

Complete contact information is available at:

https://pubs.acs.org/10.1021/acscatal.1c02074

\section{Author Contributions}

All authors have given approval to the final version of the manuscript.

\section{Notes}

The authors declare no competing financial interest.

\section{ACKNOWLEDGMENTS}

J.-D.G., S.C., and U.K. gratefully acknowledge the DFG for financial support as a part of the Priority Program SPP 2080 "Catalysts and reactors under dynamic conditions for energy storage and conversion" within the grants GR 3987/15-1 (J.D.G.), CH 1763/3-1 (S.C.), and KR 3850/8-1 (U.K.). We are grateful to SLS (SuperXAS beamline) for providing beamtime for this study. We further acknowledge funding support from the National Science Foundation (NSF) through the NSF CAREER award (Grant no. CBET-1941204). This work used the Extreme Science and Engineering Discovery Environment (XSEDE), ${ }^{64}$ which is supported by the National Science Foundation grant number ACI-1548562 through allocation TG-CHE170029. We thank Dr. Maarten Nachtegaal for his support during XAS experiments and discussion, as well as Dr. Juan Salaner Herranz for operating the operando XAS cell.

\section{REFERENCES}

(1) Katsounaros, I.; Cherevko, S.; Zeradjanin, A. R.; Mayrhofer, K. J. Oxygen electrochemistry as a cornerstone for sustainable energy conversion. Angew. Chem., Int. Ed. 2014, 53, 102-121.

(2) Kalz, K. F.; Kraehnert, R.; Dvoyashkin, M.; Dittmeyer, R.; Glaser, R.; Krewer, U.; Reuter, K.; Grunwaldt, J.-D. Future Challenges 
in Heterogeneous Catalysis: Understanding Catalysts under Dynamic Reaction Conditions. ChemCatChem 2017, 9, 17-29.

(3) Carmo, M.; Fritz, D. L.; Merge, J.; Stolten, D. A comprehensive review on PEM water electrolysis. Int. J. Hydrogen Energy 2013, 38, 4901-4934.

(4) Cherevko, S.; Zeradjanin, A. R.; Topalov, A. A.; Kulyk, N.; Katsounaros, I.; Mayrhofer, K. J. J. Dissolution of Noble Metals during Oxygen Evolution in Acidic Media. ChemCatChem 2014, 6, 2219-2223.

(5) Cherevko, S.; Geiger, S.; Kasian, O.; Kulyk, N.; Grote, J.-P.; Savan, A.; Shrestha, B. R.; Merzlikin, S.; Breitbach, B.; Ludwig, A.; Mayrhofer, K. J. J. Oxygen and hydrogen evolution reactions on $\mathrm{Ru}$, $\mathrm{RuO}_{2}$, Ir, and $\mathrm{IrO}_{2}$ thin film electrodes in acidic and alkaline electrolytes: A comparative study on activity and stability. Catal. Today 2016, 262, 170-180.

(6) Xu, W.; Haarberg, G. M.; Sunde, S.; Seland, F.; Ratvik, A. P.; Zimmerman, E.; Shimamune, T.; Gustavsson, J.; Åkre, T. Calcination Temperature Dependent Catalytic Activity and Stability of $\mathrm{IrO}_{2}-$ $\mathrm{Ta}_{2} \mathrm{O}_{5}$ Anodes for Oxygen Evolution Reaction in Aqueous Sulfate Electrolytes. J. Electrochem. Soc. 2017, 164, F895-F900.

(7) Lin, Q.; Zhu, Y.; Hu, Z.; Yin, Y.; Lin, H.-J.; Chen, C.-T.; Zhang, $\mathrm{X}$.; Shao, Z.; Wang, H. Boosting the oxygen evolution catalytic performance of perovskites via optimizing calcination temperature. $J$. Mater. Chem. A 2020, 8, 6480-6486.

(8) Liu, B.; Wang, C.; Chen, Y.; Ma, B.; Zhang, J. Effects of Calcination Temperature on the Surface Morphology and Electrocatalytic Properties of $\mathrm{Ti} / \mathrm{IrO}_{2}-\mathrm{ZrO}_{2}$ Anodes in an Oxygen Evolution Application. J. Electrochem. Soc. 2018, 165, F1192-F1198.

(9) Geiger, S.; Kasian, O.; Ledendecker, M.; Pizzutilo, E.; Mingers, A. M.; Fu, W. T.; Diaz-Morales, O.; Li, Z. Z.; Oellers, T.; Fruchter, L.; Ludwig, A.; Mayrhofer, K. J. J.; Koper, M. T. M.; Cherevko, S. The stability number as a metric for electrocatalyst stability benchmarking. Nat. Catal. 2018, 1, 508-515.

(10) Man, I. C.; Su, H. Y.; Calle-Vallejo, F.; Hansen, H. A.; Martinez, J. I.; Inoglu, N. G.; Kitchin, J.; Jaramillo, T. F.; Norskov, J. K.; Rossmeisl, J. Universality in Oxygen Evolution Electrocatalysis on Oxide Surfaces. ChemCatChem 2011, 3, 1159-1165.

(11) Ping, Y.; Nielsen, R. J.; Goddard, W. A., 3rd The Reaction Mechanism with Free Energy Barriers at Constant Potentials for the Oxygen Evolution Reaction at the $\mathrm{IrO}_{2}$ (110) Surface. J. Am. Chem. Soc. 2017, 139, 149-155.

(12) Shi, Z.; Wang, X.; Ge, J.; Liu, C.; Xing, W. Fundamental understanding of the acidic oxygen evolution reaction: mechanism study and state-of-the-art catalysts. Nanoscale 2020, 12, 1324913275.

(13) Zhu, K.; Shi, F.; Zhu, X.; Yang, W. The roles of oxygen vacancies in electrocatalytic oxygen evolution reaction. Nano Energy 2020, 73, No. 104761.

(14) Grimaud, A.; Demortière, A.; Saubanère, M.; Dachraoui, W.; Duchamp, M.; Doublet, M.-L.; Tarascon, J.-M. Activation of surface oxygen sites on an iridium-based model catalyst for the oxygen evolution reaction. Nat. Energy 2017, 2, No. 16189.

(15) Zagalskaya, A.; Evazzade, I.; Alexandrov, V. Ab Initio Thermodynamics and Kinetics of the Lattice Oxygen Evolution Reaction in Iridium Oxides. ACS Energy Lett. 2021, 1124-1133.

(16) Grunwaldt, J.-D.; Molenbroek, A. M.; Topsøe, N. Y.; Topsøe, H.; Clausen, B. S. In Situ Investigations of Structural Changes in $\mathrm{Cu} /$ ZnO Catalysts. J. Catal. 2000, 194, 452-460.

(17) Duarte, R. B.; Safonova, O. V.; Krumeich, F.; van Bokhoven, J. A. Atomically dispersed rhodium on a support: the influence of a metal precursor and a support. Phys. Chem. Chem. Phys. 2014, 16, 26553-26560.

(18) Keresszegi, C.; Grunwaldt, J.-D.; Mallat, T.; Baiker, A. Liquid phase oxidation of alcohols with oxygen: in situ monitoring of the oxidation state of Bi-promoted Pd/Al2O3. Chem. Commun. 2003, 2304-2305.

(19) Padmos, J. D.; Personick, M. L.; Tang, Q.; Duchesne, P. N.; Jiang, D. E.; Mirkin, C. A.; Zhang, P. The surface structure of silver- coated gold nanocrystals and its influence on shape control. Nat. Commun. 2015, 6, No. 7664.

(20) Baurecht, D.; Fringeli, U. P. Quantitative modulated excitation Fourier transform infrared spectroscopy. Rev. Sci. Instrum. 2001, 72, $3782-3792$

(21) Ferri, D.; Newton, M. A.; Nachtegaal, M. Modulation Excitation X-Ray Absorption Spectroscopy to Probe Surface Species on Heterogeneous Catalysts. Top. Catal. 2011, 54, 1070-1078.

(22) König, C. F. J.; Schildhauer, T. J.; Nachtegaal, M. Methane synthesis and sulfur removal over a Ru catalyst probed in situ with high sensitivity X-ray absorption spectroscopy. J. Catal. 2013, 305, $92-100$.

(23) König, C. F. J.; van Bokhoven, J. A.; Schildhauer, T. J.; Nachtegaal, M. Quantitative Analysis of Modulated Excitation X-ray Absorption Spectra: Enhanced Precision of EXAFS Fitting. J. Phys. Chem. C 2012, 116, 19857-19866.

(24) Lu, Y.; Keav, S.; Marchionni, V.; Chiarello, G. L.; Pappacena, A.; Di Michiel, M.; Newton, M. A.; Weidenkaff, A.; Ferri, D. Ageing induced improvement of methane oxidation activity of $\mathrm{Pd} / \mathrm{YFeO}_{3}$. Catal. Sci. Technol. 2014, 4, 2919.

(25) Urakawa, A.; Bürgi, T.; Baiker, A. Kinetic analysis using squarewave stimulation in modulation excitation spectroscopy: Mixing property of a flow-through PM-IRRAS cell. Chem. Phys. 2006, 324, 653-658.

(26) Urakawa, A.; van Beek, W.; Monrabal-Capilla, M.; GalánMascarós, J. R.; Palin, L.; Milanesio, M. Combined, Modulation Enhanced X-ray Powder Diffraction and Raman Spectroscopic Study of Structural Transitions in the Spin Crossover Material $[\mathrm{Fe}(\mathrm{Htrz})$ 2(trz)](BF4). J. Phys. Chem. C 2011, 115, 1323-1329.

(27) Müller, P.; Hermans, I. Applications of Modulation Excitation Spectroscopy in Heterogeneous Catalysis. Ind. Eng. Chem. Res. 2017, $56,1123-1136$.

(28) Chiarello, G. L.; Ferri, D. Modulated excitation extended X-ray absorption fine structure spectroscopy. Phys. Chem. Chem. Phys. 2015, 17, 10579-10591.

(29) Müller, O.; Nachtegaal, M.; Just, J.; Lützenkirchen-Hecht, D.; Frahm, R. Quick-EXAFS setup at the SuperXAS beamline for in situ $\mathrm{X}$-ray absorption spectroscopy with $10 \mathrm{~ms}$ time resolution. J. Synchrotron Radiat. 2016, 23, 260-266.

(30) Nattino, F.; Marzari, N. Operando XANES from first-principles and its application to iridium oxide. Phys. Chem. Chem. Phys. 2020, 22, 10807-10818.

(31) Reksten, A. H.; Russell, A. E.; Richardson, P. W.; Thompson, S. J.; Mathisen, K.; Seland, F.; Sunde, S. An in situ XAS study of high surface-area $\mathrm{IrO}_{2}$ produced by the polymeric precursor synthesis. Phys. Chem. Chem. Phys. 2020, 22, 18868-18881.

(32) Abbott, D. F.; Lebedev, D.; Waltar, K.; Povia, M.; Nachtegaal, M.; Fabbri, E.; Copéret, C.; Schmidt, T. J. Iridium Oxide for the Oxygen Evolution Reaction: Correlation between Particle Size, Morphology, and the Surface Hydroxo Layer from Operando XAS. Chem. Mater. 2016, 28, 6591-6604.

(33) Hillman, A. R.; Skopek, M. A.; Gurman, S. J. X-ray spectroscopy of electrochemically deposited iridium oxide films: detection of multiple sites through structural disorder. Phys. Chem. Chem. Phys. 2011, 13, 5252-5263.

(34) Nong, H. N.; Falling, L. J.; Bergmann, A.; Klingenhof, M.; Tran, H. P.; Spori, C.; Mom, R.; Timoshenko, J.; Zichittella, G.; KnopGericke, A.; Piccinin, S.; Perez-Ramirez, J.; Cuenya, B. R.; Schlogl, R.; Strasser, P.; Teschner, D.; Jones, T. E. Key role of chemistry versus bias in electrocatalytic oxygen evolution. Nature 2020, 587, 408-413.

(35) Serrer, M.-A.; Gaur, A.; Jelic, J.; Weber, S.; Fritsch, C.; Clark, A. H.; Saraçi, E.; Studt, F.; Grunwaldt, J.-D. Structural dynamics in NiFe catalysts during $\mathrm{CO}_{2}$ methanation - role of iron oxide clusters. Catal. Sci. Technol. 2020, 10, 7542-7554.

(36) Rehr, J. J.; Kas, J. J.; Vila, F. D.; Prange, M. P.; Jorissen, K. Parameter-free calculations of X-ray spectra with FEFF9. Phys. Chem. Chem. Phys. 2010, 12, 5503-5513. 
(37) Teoh, W. Y.; Amal, R.; Mädler, L. Flame spray pyrolysis: An enabling technology for nanoparticles design and fabrication. Nanoscale 2010, 2, 1324-1347.

(38) Mädler, L.; Kammler, H. K.; Mueller, R.; Pratsinis, S. E. Controlled synthesis of nanostructured particles by flame spray pyrolysis. J. Aerosol Sci. 2002, 33, 369-389.

(39) Arminio-Ravelo, J. A.; Quinson, J.; Pedersen, M. A.; Kirkensgaard, J. J. K.; Arenz, M.; Escudero-Escribano, M. Synthesis of Iridium Nanocatalysts for Water Oxidation in Acid: Effect of the Surfactant. ChemCatChem 2020, 12, 1282-1287.

(40) Schuppert, A. K.; Topalov, A. A.; Katsounaros, I.; Klemm, S. O.; Mayrhofer, K. J. J. A Scanning Flow Cell System for Fully Automated Screening of Electrocatalyst Materials. J. Electrochem. Soc. 2012, 159, F670-F675.

(41) Povia, M.; Abbott, D. F.; Herranz, J.; Heinritz, A.; Lebedev, D.; Kim, B.-J.; Fabbri, E.; Patru, A.; Kohlbrecher, J.; Schäublin, R.; Nachtegaal, M.; Copéret, C.; Schmidt, T. J. Operando X-ray characterization of high surface area iridium oxides to decouple their activity losses for the oxygen evolution reaction. Energy Environ. Sci. 2019, 12, 3038-3052.

(42) Binninger, T.; Fabbri, E.; Patru, A.; Garganourakis, M.; Han, J.; Abbott, D. F.; Sereda, O.; Kötz, R.; Menzel, A.; Nachtegaal, M.; Schmidt, T. J. Electrochemical Flow-Cell Setup for In Situ X-ray Investigations. J. Electrochem. Soc. 2016, 163, H906-H912.

(43) Mamaca, N.; Mayousse, E.; Arrii-Clacens, S.; Napporn, T. W.; Servat, K.; Guillet, N.; Kokoh, K. B. Electrochemical activity of ruthenium and iridium based catalysts for oxygen evolution reaction. Appl. Catal., B 2012, 111-112, 376-380.

(44) Von Dreifus, D.; de Oliveira, A. J. A.; do Rosario, A. V.; Pereira, E. C. Magnetic and Structural Characterization of $\mathrm{IrO}_{2}$ and $\mathrm{Co}: \mathrm{IrO}_{2}$ Samples Synthesized via Pechini Method. J. Supercond. Novel Magn. 2012, 26, 2319-2321.

(45) Reksten, A. H.; Russell, A. E.; Richardson, P. W.; Thompson, S. J.; Mathisen, K.; Seland, F.; Sunde, S. Strategies for the analysis of the elemental metal fraction of Ir and Ru oxides via XRD, XANES, and EXAFS. Phys. Chem. Chem. Phys. 2019, 21, 12217-12230.

(46) Cherevko, S.; Reier, T.; Zeradjanin, A. R.; Pawolek, Z.; Strasser, P.; Mayrhofer, K. J. J. Stability of nanostructured iridium oxide electrocatalysts during oxygen evolution reaction in acidic environment. Electrochem. Commun. 2014, 48, 81-85.

(47) Geiger, S.; Kasian, O.; Shrestha, B. R.; Mingers, A. M.; Mayrhofer, K. J. J.; Cherevko, S. Activity and Stability of Electrochemically and Thermally Treated Iridium for the Oxygen Evolution Reaction. J. Electrochem. Soc. 2016, 163, F3132-F3138.

(48) Escalera-López, D.; Czioska, S.; Geppert, J.; Boubnov, A.; Röse, P.; Saraçi, E.; Krewer, U.; Grunwaldt, J.-D.; Cherevko, S. Phase- and Surface Composition Dependent Electrochemical Stability of Ir-Ru Nanoparticles during Oxygen Evolution Reaction. ACS Catal. 2021, 11, 9300-9316.

(49) Minguzzi, A.; Lugaresi, O.; Achilli, E.; Locatelli, C.; Vertova, A.; Ghigna, P.; Rondinini, S. Observing the oxidation state turnover in heterogeneous iridium-based water oxidation catalysts. Chem. Sci. 2014, 5, 3591.

(50) Zabilskiy, M.; Sushkevich, V. L.; Palagin, D.; Newton, M. A.; Krumeich, F.; van Bokhoven, J. A. The unique interplay between copper and zinc during catalytic carbon dioxide hydrogenation to methanol. Nat. Commun. 2020, 11, No. 2409.

(51) Olliges-Stadler, I.; Stötzel, J.; Koziej, D.; Rossell, M. D.; Grunwaldt, J.-D.; Nachtegaal, M.; Frahm, R.; Niederberger, M. Study of the Chemical Mechanism Involved in the Formation of Tungstite in Benzyl Alcohol by the Advanced QEXAFS Technique. Chem. Eur. J. 2012, 18, 2305-2312.

(52) Stötzel, J.; Frahm, R.; Kimmerle, B.; Nachtegaal, M.; Grunwaldt, J.-D. Oscillatory Behavior during the Catalytic Partial Oxidation of Methane: Following Dynamic Structural Changes of Palladium Using the QEXAFS Technique. J. Phys. Chem. C 2012, 116, 599-609.

(53) Sun, W.; Wang, Z.; Zhou, Z.; Wu, Y.; Zaman, W. Q.; Tariq, M.; Cao, L. M.; Gong, X. Q.; Yang, J. A promising engineering strategy for water electro-oxidation iridate catalysts via coordination distortion. Chem. Commun. 2019, 55, 5801-5804.

(54) da Silva, G. C.; Perini, N.; Ticianelli, E. A. Effect of temperature on the activities and stabilities of hydrothermally prepared $\mathrm{IrO}_{x}$ nanocatalyst layers for the oxygen evolution reaction. Appl. Catal., $B$ 2017, 218, 287-297.

(55) Pham, C. V.; Bühler, M.; Knöppel, J.; Bierling, M.; Seeberger, D.; Escalera-López, D.; Mayrhofer, K. J. J.; Cherevko, S.; Thiele, S. $\mathrm{IrO}_{2}$ coated $\mathrm{TiO}_{2}$ core-shell microparticles advance performance of low loading proton exchange membrane water electrolyzers. Appl. Catal., B 2020, 269, No. 118762.

(56) Rossmeisl, J.; Qu, Z. W.; Zhu, H.; Kroes, G. J.; Nørskov, J. K. Electrolysis of water on oxide surfaces. J. Electroanal. Chem. 2007, 607, $83-89$.

(57) Briquet, L. G. V.; Sarwar, M.; Mugo, J.; Jones, G.; Calle-Vallejo, F. A New Type of Scaling Relations to Assess the Accuracy of Computational Predictions of Catalytic Activities Applied to the Oxygen Evolution Reaction. ChemCatChem 2017, 9, 1261-1268.

(58) Gauthier, J. A.; Dickens, C. F.; Chen, L. D.; Doyle, A. D.; Nørskov, J. K. Solvation Effects for Oxygen Evolution Reaction Catalysis on $\mathrm{IrO}_{2}(110)$. J. Phys. Chem. C 2017, 121, 11455-11463.

(59) Klyukin, K.; Zagalskaya, A.; Alexandrov, V. Ab Initio Thermodynamics of Iridium Surface Oxidation and Oxygen Evolution Reaction. J. Phys. Chem. C 2018, 122, 29350-29358.

(60) Geppert, J.; Kubannek, F.; Röse, P.; Krewer, U. Identifying the Oxygen Evolution Mechanism by Microkinetic Modelling of Cyclic Voltammograms. Electrochim. Acta 2021, 380, No. 137902.

(61) Siracusano, S.; Hodnik, N.; Jovanovic, P.; Ruiz-Zepeda, F.; Šala, M.; Baglio, V.; Aricò, A. S. New insights into the stability of a high performance nanostructured catalyst for sustainable water electrolysis. Nano Energy 2017, 40, 618-632.

(62) Kasian, O.; Geiger, S.; Li, T.; Grote, J.-P.; Schweinar, K.; Zhang, S.; Scheu, C.; Raabe, D.; Cherevko, S.; Gault, B.; Mayrhofer, K. J. J. Degradation of iridium oxides via oxygen evolution from the lattice: correlating atomic scale structure with reaction mechanisms. Energy Environ. Sci. 2019, 12, 3548-3555.

(63) Schweinar, K.; Gault, B.; Mouton, M.; Kasian, O. Lattice Oxygen Exchange in Rutile $\mathrm{IrO}_{2}$ during the Oxygen Evolution Reaction. J. Phys. Chem. Lett. 2020, 11, 5008-5014.

(64) Towns, J.; Cockerill, T.; Dahan, M.; Foster, I.; Gaither, K.; Grimshaw, A.; Hazlewood, V.; Lathrop, S.; Lifka, D.; Peterson, G. D.; Roskies, R.; Scott, J. R.; Wilkins-Diehr, N. XSEDE: Accelerating Scientific Discovery. Comput. Sci. Eng. 2014, 16, 62-74. 